\title{
Using remote-sensing data to assess habitat selection of a declining passerine at two spatial scales
}

Nica Huber, Felix Kienast, Christian Ginzler, Gilberto Pasinelli

N. Huber (corresponding author) / F. Kienast / C. Ginzler

Swiss Federal Institute for Forest, Snow and Landscape Research WSL

Zürcherstrasse 111

CH-8903 Birmensdorf, Switzerland

e-mail: nica.huber@wsl.ch

Current e-mail: nica.huber@usys.ethz.ch

phone: +41 447392591 / fax: +41 447392215

G. Pasinelli

Swiss Ornithological Institute

Seerose 1

CH-6204-Sempach, Switzerland

Date of revised manuscript draft: March 04, 2016

Manuscript word count (excluding references): 6590 (8009 with Tables and Figure legends)

This document is the accepted manuscript version of the following article:

Huber, N., Kienast, F., Ginzler, C., \& Pasine11i, G. (2016). Using remote-sensing data to assess habitat selection of a declining passerine at two spatial scales. Landscape Ecology, 31(9), 1919-1937. https://doi.org/10.1007/s10980-016-0370-1 


\begin{abstract}
Context Detailed information on habitat needs is integral to identify conservation measures for declining species. However, field data on habitat structure is typically limited in extent. Remote sensing has the potential to overcome these limitations of field-based studies.

Objective We aimed to assess abiotic and biotic characteristics of territories used by the declining wood warbler (Phylloscopus sibilatrix), a forest-interior migratory passerine, at two spatial scales by evaluating a priori expectations of habitat selection patterns.

Methods First, territories established by males before pairing, referred to as prebreeding territories, were compared to pseudo-absence control areas located in the wider

10 forested landscape (first spatial scale, $\mathrm{N}_{\text {territories }}=66, \mathrm{~N}_{\text {controls }}=66$ ). Second, breeding territories of paired wood warblers were compared to true-absence control areas located immediately closeby in the forest ( second spatial scale, $\mathrm{N}_{\text {territories }}=78, \mathrm{~N}_{\text {controls }}=78$ ). Habitat variables predominantly described forest structure and were mainly based on first and last pulse lidar (light detection and ranging) data.
\end{abstract}

Results Occurrence of pre-breeding territories was related to vegetation height, vertical diversity and stratification, canopy cover, inclination and solar radiation. Occurrence of breeding territories was associated to vegetation height, vertical diversity and inclination.

Conclusions Territory selection at the two spatial scales addressed was governed by similar factors. With respect to conservation, habitat suitability for wood warblers could be retained by maintaining a shifting mosaic of stand ages and structures at large spatial scales. Moreover, leaf-off lidar variables have the potential to contribute to understanding the ecological niche of species in predominantly deciduous forests.

\title{
Keywords
}

Birds; forest structure; GLMMs; habitat model; leaf-off; lidar; Phylloscopus sibilatrix; 25 Switzerland; Sylviidae; wood warbler 


\section{Introduction}

Detailed knowledge of the habitat needs of declining species is crucial for various applications, including habitat protection (e.g. Whittingham et al. 2005), the restoration of species to previously occupied habitat (Merrill et al. 1999), the identification of dispersal

30 corridors (Chetkiewicz and Boyce 2009) or for predicting species distribution and locating potentially suitable habitat (e.g. Luoto et al. 2002). Studies on habitat needs and habitat suitability require information on potentially influential variables measured at the appropriate scale (spatial grain and extent). However, information on habitat variables based on field data is often limited because data collection is usually time consuming and spatially restricted.

35 Remote sensing (hereafter RS) has therefore become an important tool for mapping ecosystems at broad spatial scales while retaining a high level of detail, thus allowing improved modeling of, for example, species' distribution and potential habitats (e.g. Sperduto and Congalton 1996). RS includes a wide range of technologies ranging from airborne sensors to satellitebased information, global positioning systems or camera tracks (Pettorelli et al. 2014). Among

40 others, methods currently used for modeling and mapping species distribution and richness are image texture (e.g. Bellis et al. 2008; Wood et al. 2013; Duncan et al. 2014; St-Louis et al. 2014), spectral mixture analysis (e.g. St-Louis et al. 2014) or image classification (e.g. Duncan et al. 2014). Typically, the RS data used in such models does not allow characterizing vertical habitat structure (Lefsky et al. 2002; Vierling et al. 2008). However, many species, especially

45 forest bird species, are associated with specific three-dimensional habitat structures (e.g. Dunlavy 1935; Shaw et al. 2002). In contrast to other RS methods, light detection and ranging (lidar) is a source of high-resolution geospatial data, providing three-dimensional information about micro-topography and the structure of ecosystems over broad spatial extents (Vierling et al. 2008; Müller et al. 2009). 
With regard to lidar-derived assessment of forest habitat suitability, species occurrence has successfully been investigated for various animal taxa such as mammals (Nelson et al. 2005; Coops et al. 2010; Jung et al. 2012; Palminteri et al. 2012) or arthropods (Müller and Brandl 2009; Vierling et al. 2011; Müller et al. 2014). In birds, forest habitat suitability based on lidar data has been estimated for several species, including grouse (Graf et al. 2009; Zellweger et al. 2013), owls (Zellweger et al. 2013), woodpeckers (Smart et al. 2012; Trainor et al. 2013; Vierling et al. 2013; Zellweger et al. 2013) and passerines (Broughton et al. 2006, 2012; Bellamy et al. 2009; Goetz et al. 2010; Farrell et al. 2013; Vogeler et al. 2013; Reidy et al. 2015).

Here, we address habitat selection of the wood warbler (Phylloscopus sibilatrix) at two spatial scales using RS data, and particularly lidar data. The species is a near-endemic to Europe classified as "least concern” (BirdLife International 2015). Nevertheless, the wood warbler has suffered long-term declines in many EU countries (EIONET 2015). Upon return from their sub-Saharan wintering areas (Hobson et al. 2014), male wood warblers start settling on the breeding grounds in early to mid-April, while females arrive on average 10 days later (Glutz von Blotzheim and Bauer 1991, Wesolowksi and Maziarz 2009). Before getting paired, pre-breeding territories defended by males are 1-3 ha in size (Glutz von Blotzheim and Bauer 1991). After pairing has occurred, territories used for breeding average 1,200-1,900 $\mathrm{m}^{2}$ (Glutz von Blotzheim and Bauer 1991). Within these breeding territories, females select a nest site on the ground (Glutz von Blotzheim and Bauer 1991). To meet the species' needs, a forest must thus offer suitable conditions at the pre-breeding territory scale as well as at the breeding territory scale. That habitat selection can differ depending on the spatial scale considered has long been recognized (Johnson 1980, Hutto 1985, Bunnell \& Huggard 1999). However, while seasonal variation in territory size (e.g. Finck 1990, Möller 1990, Pasinelli et al. 2001, Wiktander et al. 2001) and seasonal changes in habitat selection (e.g. Wikar et al. 2008, Brambilla et al. 2012) have been reported, particularly for non-migratory species, surprisingly 
little is known about whether habitat selection by migratory songbirds prior to breeding (i.e. after settlement) and during breeding (i.e. after pair formation and during brood rearing) differs. Knowing what constitutes suitable habitats at the pre-breeding stage and the breeding stage, respectively, and managing for these habitat types, would ensure that habitats suitable for both settlement and breeding will be preserved. It is possible that the same habitat types or structures affect both settlement and breeding, as breeding territories are contained within prebreeding territories. However, habitat types or structures in breeding territories might differ from the larger pre-breeding territories, for example when breeding territories need to provide specific food resources and/or specific habitat structure promoting successful breeding. We thus addressed the following questions: 1) do the habitat characteristics of pre-breeding territories differ from what is available in the wider forested landscape? And 2) do the habitat characteristics of breeding territories differ from what is available in the immediate forest vicinity? Based on known habitat requirements, we evaluated a priori expectations of the relationships between wood warbler occurrence and habitat factors (Methods/Expectations).

\section{Methods}

\section{Study species}

The wood warbler is a ground-nesting, long-distance migratory passerine with a distinctly European range. The species selects habitats predominantly located in broadleaf and

95 mixed deciduous forest at low to medium altitudes. Within the forest, stands are used that feature trees with a height of at least 8-10 m, an open stem space and a rather closed canopy (Quelle and Tiedemann 1972; Glutz von Blotzheim and Bauer 1991). Older stands (Quelle and Tiedemann 1972; Reinhardt and Bauer 2009; Pasinelli et al. 2016) and stands with heterogeneous tree height (Pavlovic 2009) are suggested to be less suitable. A lush herb and shrub layer is avoided, while grass and sedge tussocks are used (Quelle and Tiedemann 1972; 
Schifferli et al. 1980; Bibby 1989; Glutz von Blotzheim and Bauer 1991; Pavlovic 2009;

Reinhardt and Bauer 2009; Mallord et al. 2012; Pasinelli et al. 2016). Several studies reported a preference for inclined areas with eastern or southerly aspects (Quelle and Tiedemann 1972; Glutz von Blotzheim and Bauer 1991; Mallord et al. 2012; Pasinelli et al. 2016).

\section{Study areas}

We initially determined areas with a relatively high abundance of wood warblers in the 10 years prior to 2010 throughout northern Switzerland based on a) the common breeding bird survey provided by the Swiss Ornithological Institute (the standardized Swiss national bird monitoring program, www.vogelwarte.ch/monitoring-common-breeding-birds.html), b) the breeding bird atlas of the canton Zurich (www.birdlifezuerich.ch), and c) www.ornitho.ch (the official birding exchange platform in Switzerland). However, during early field work in 2010 (Gerber 2011, Grendelmeier et al. 2015), it became evident that some of these areas no longer had any breeding birds, leaving us with 16 intensively searched study areas (Fig. 1). These study areas ranged in size from 0.18 to $2.35 \mathrm{~km}^{2}$ (App. 1) and were all part of large woodlands consisting of deciduous and mixed-forest stands dominated by European beech (Fagus sylvatica), with coniferous tree species interspersed (Picea abis, Abies alba, Pinus sylvestris). Boundaries of the study areas were determined by landscape elements such as forest edge, valleys or strong changes in forest structure (e.g. young re-growths or coniferous plantations). Elevation of the study areas ranges between 543 and 1,022 m a.s.1. Study areas are characterized by cold winters, warm and wet summer months and mean yearly precipitation rates from 800 to $1,500 \mathrm{~mm}$ (MeteoSchweiz 2014). Mean annual minimum and maximum temperature is $5.4{ }^{\circ} \mathrm{C}$ and $11.8^{\circ} \mathrm{C}$, respectively.

\#Fig. 1 approximately here\# 


\section{Bird mapping procedure}

Wood warbler occurrence was mapped between 2010 and 2012 annually from midApril on by listening for the distinct wood warbler song. In all 16 intensively searched study areas, we used the coordinates of previous sightings as rough starting points, from where we extensively searched for the species. If no wood warblers were heard or observed, we played $10 \mathrm{~s}$ playbacks of wood warbler songs every $300 \mathrm{~m}$ to avoid overlooking territories. As soon as birds responded, we stopped the playback. On average, each study area was checked once a week until early July. Once territories had been established, they were regularly checked for the presence of females and nests. The nest position was mapped with a handheld GPS. Due to the regular observer presence, a narrow search grid and the use of playback, it is highly probable that all nests within a study area were found.

\section{Definition of sample areas}

We defined two types of sample areas differing in their occupation state, namely territories (occupied) and control areas (unoccupied). Because no exact information about the location of the nest relative to the defended area was available, we approximated territories by circles centered on the nest. The nest location was thus used as a proxy for the center of a territory. We did not aim at measuring nest-site selection within territories $\left(4^{\text {th }}\right.$ order selection sensu Johnson 1980). Pre-breeding territory size of the wood warbler is reported to be approximately $10,000-30,000 \mathrm{~m}^{2}$, corresponding to a circle with radius of at least $56 \mathrm{~m}$. Breeding-territory size ranges from $1,200-1,900 \mathrm{~m}^{2}$, corresponding to a circle with mean radius of $22.25 \mathrm{~m}$ (Glutz von Blotzheim and Bauer 1991). To reduce the risk of including unsuitable habitat, radii were reduced to 80 percent of the sizes given above. Thus, pre-breeding-territory size was approximated by a circular area of $6,648 \mathrm{~m}^{2}$ and breeding territory size by a circular area of $1,000 \mathrm{~m}^{2}$, both centered on the nest location.

To compare habitat characteristics of pre-breeding and breeding territories to what is available in the wider forested landscape (question 1) and in the immediate forest vicinity 
(question 2), respectively, two types of control areas were defined. In the following, we refer to control areas relating to question 1 as "pseudo-absences" and to control areas relating to question 2 as "field-absences". To address question 1, for each pre-breeding territory in a specific study area, one pseudo-absence was randomly selected outside the intensively searched study area based on the following criteria: 1) located in woodland, not recently affected by large, natural disturbance (e.g. fire, wind throw) 2) located at a distance between 500 and 2,000 $\mathrm{m}$ from the nest of the respective territory, 3) located at a distance of at least 500 $\mathrm{m}$ from all the other nests and centers of the field-absences (see below) of the respective study 160 area. A range of distances was needed to fulfill criteria 1) and 3). The choice of the distance is subject to a trade-off. To allow for increased environmental variation, the distance should be as large as possible. However, with increasing distance, the probability rises that possibly existing territories are mistakenly selected as pseudo-absence. A qualitative assessment following the selection process revealed that $98 \%$ of the defined pseudo-absences did not correspond to the

165 species' typical habitat description (Alex Grendelmeier, pers. comm.). To address question 2, for each breeding territory, one field-absence was defined within the intensively searched study area with its center located 200-300 m from the nest position. First, eight possible fieldabsences (i.e. X-Y-coordinates) 200-300 $\mathrm{m}$ from the nest of the respective breeding territory were defined in the four cardinal (N, E, S, W) and four intercardinal (NE, SE, SW and NW)

170 directions. To avoid trivial results, field-absences with habitats known to be unsuitable for wood warblers (non-forest areas, forest clearings, purely coniferous forest patches, young regrowths and plantations) were ruled out. Also, field-absences closer than $50 \mathrm{~m}$ to other breeding territories in the same year were excluded. Of the non-excluded field-absences, one was randomly selected. Absence of wood warblers in retained field-absences was confirmed 175 with playback.

Because some territories partly overlapped among the three study years, analyses were restricted to territories not overlapping more than $10 \%$ with each other. Selection of 
overlapping territories followed two principles: (1) if two territories overlapped more than $10 \%$ with one another, one of the two was randomly selected for use in the analyses, the other one

180 discarded; (2) if more than two territories overlapped more than $10 \%$ with one another, territories to be excluded were selected so as to minimize the total number of territories excluded. The same principles applied to field-absences overlapping between study years. We ended up with 66 pre-breeding territories paired to 66 pseudo-absences and 78 breeding territories paired to 78 field-absences (App. 1).

$185 R S$ variables

The RS data was processed in the Geographic Information System ESRI ArcInfo, PyScripter for Python and R. LAStools were used for the operational processing of lidar data (Isenburg 2012). The RS variables (Table 1) were grouped into lidar variables and non-lidar RS variables, respectively, and assigned to five thematic groups that comprised variables

190 measuring similar aspects of the environment. All variables were calculated for both prebreeding and breeding territories, respectively, and their associated control areas.

\section{Lidar variables}

First and last return lidar data was nationally available in the form of classified point clouds, namely the digital terrain model (DTM) and the digital surface model (DSM) (DTM-

195 AV, DOM-AV (C) 2014 swisstopo 5704000 000; swisstopo 2012). Mean point density was 1.5 $\mathrm{m}^{-2}$ for the sample areas analyzed. The standard deviation of height accuracy was $1.5 \mathrm{~m}$ in forested areas, as reported by the data provider. The interpolation of the DTM into a regular 2 $m$ grid yields the swissALTI3D (swisstopo 2013). In addition, a normalized digital surface model (nDSM), representing vegetation height, was calculated by subtracting the DSM from 200 the swissALTI3D. Values deviating negatively by three or more times the standard deviation from the mean of all negative values of the nDSM were treated as outliers and excluded from further analyses (Grubbs 1969). 
For 14 out of 16 study areas, lidar data were collected in 2001, for the other two in 2002. Eleven study areas were flown in February, four in April, and one in December and

205 January, respectively. Forest structure determined from lidar data very likely reflects conditions during wood warbler territory mapping conducted 10 years later because areas strongly impacted by disturbances were not suitable for territory establishment anyway and, if disturbances existed, excluded as both field-absences and pseudo-absences (see above). Moreover, most study areas are located in forests managed last 20 to 50 years ago (Duc et al. 210 2010). Further, a case study showed that a 6-year difference between the collection of lidar data and bird data had a minimal effect on mapped avian distribution patterns in an undisturbed coniferous forest (Vierling et al. 2014). That lidar data collection occurred outside the growing season could be critical in terms of tree species composition (deciduous vs. non-deciduous) and temporal displacement between habitat selection and habitat description. For deciduous trees,

215 lidar signals under leaf-off conditions can only be intercepted by branches and stems, leading to a higher proportion of ground reflections than under leaf-on conditions (Brandtberg et al. 2003). Further, under leaf-off conditions, variability of canopy height is significantly higher and many canopy height and density measures are lower for deciduous forests compared to leaf-on conditions (Brandtberg et al. 2003; Næsset 2005). In contrast, non-deciduous trees will 220 not be affected by changes from leaf-off to leaf-on conditions (Ørka et al. 2010). For the application in this study, however, the most important issue is that relative differences in forest structure characteristics are captured by the lidar variables (i.e. a closed stand can be distinguished from a scattered stand). Moreover, recent studies demonstrated that leaf-off lidar sampled for the purpose of terrain mapping is valuable for predicting forest characteristics even 225 for deciduous forests (Hawbaker et al. 2010, Wasser et al. 2013; Parent and Volin 2014).

Height and vertical diversity variables - Variables of this thematic group describe vegetation height $(\mathrm{VH})$ and canopy height $(\mathrm{CH})$, and the vertical diversity within $\mathrm{VH}$ and $\mathrm{CH}$. VH equates to the nDSM. $\mathrm{CH}$ is represented by the maximum lidar signal for each cell in a $2 \times 2$ 
m grid laid over every sample area. On this basis, the following variables were calculated for the pre-breeding and breeding territories as well as their associated control areas (Table 1): mean vegetation height (mean $\mathrm{VH})$, mean canopy height (mean $\mathrm{CH}$ ), maximum vegetation height $(\max V H)$, the $95 \%$ percentile of vegetation height (VH95), the standard deviation of vegetation height $(s d V H)$ and the standard deviation of canopy height $(s d C H)$. MeanVH is an index of vegetation height in general, whereas mean $\mathrm{CH}$ refers specifically to the upper canopy layer. The standard deviation provides a measure of the vertical variation of $\mathrm{VH}$ and $\mathrm{CH}$, respectively. A small standard deviation arises from sample areas with a homogeneous vegetation or tree height, while a high standard deviation reflects a heterogeneous vegetation or tree height (Müller et al. 2009). Additionally, the following variables refer to the tree layer: mean vegetation height above $3 \mathrm{~m}($ mean $V H>3 \mathrm{~m})$, mean canopy height above $3 \mathrm{~m}$ (mean $\mathrm{CH}>3 \mathrm{~m})$ and the standard deviation of canopy height above $3 \mathrm{~m}(\mathrm{sdCH}>3 \mathrm{~m})$. These three variables were calculated including only laser signals reflecting from objects more than 3 $\mathrm{m}$ above ground. Mean vegetation height less than $3 \mathrm{~m}($ meanVH<3m) refers to the shrub and regeneration layer and is represented by the arithmetic mean of all lidar signals less than $3 \mathrm{~m}$ above ground.

Vertical stratification variables - Stratification describes the distribution of different life forms or age classes existing at specific heights, e.g. trees, shrubs and herbs (Parker and Brown 2000, Park 2007). In this study, three vegetation layers were analyzed based on their penetration rates: pen50_2 refers to the tree layer, pen 10_2 to the mid-story and pen $5 \_1$ to the shrub and regeneration layer. A high penetration rate indicates a sparse development of the corresponding vegetation layer, while a low penetration rate originates when the vegetation layer of interest is well developed (Müller et al. 2009). To calculate pen50_2, the sum of all lidar signals below $2 \mathrm{~m}$ above ground was divided by the sum of all lidar signals below $50 \mathrm{~m}$ above ground. Pen10_2 is described by the ratio of the sum of all lidar signals below $2 \mathrm{~m}$ and 
the sum of all lidar signals below $10 \mathrm{~m}$. Pen 5 _ 1 equals to the ratio of the sum of all lidar 255 signals below $1 \mathrm{~m}$ and the sum of all lidar signals below $5 \mathrm{~m}$ (Müller et al. 2009).

Canopy cover variables - This group contains variables describing canopy cover at four height levels, namely at $3 \mathrm{~m}$ (meanCC), $10 \mathrm{~m}($ meanCC_10m), $15 \mathrm{~m}($ meanCC_15m) and $20 \mathrm{~m}$ (meanCC_20m) above ground. The calculation of canopy cover was based on the data of $\mathrm{CH}$. The respective canopy cover results from the ratio of the number of $2 \times 2 \mathrm{~m}$ cells with values above the particular height level and the total number of $2 \times 2 \mathrm{~m}$ cells per sample area. Canopy cover is higher, the more lidar signals are present above the particular height level.

Geography-related variables - This group only comprises one lidar variable, namely slope. Slope values were derived from the swissALTI3D and averaged per sample area. Non-lidar RS variables

In addition to the lidar variables, the following non-lidar RS variables were calculated and assigned to the geography-related variables: potential direct solar radiation in March ( $r \_$march), forest type (forest_type) and distance to forest edge (dist_f). $R \_$march values were derived for from the digital height model DHM25 (C) 2014 swisstopo 5704000000 (swisstopo 2015) following Zimmermann and Kienast (1999). Values were resampled to a resolution of

$2705 \times 5 \mathrm{~m}$ and averaged per sample area. Forest_type values were derived from the vegetation classification provided by the Swiss Federal Statistical Office (2010), classifying 25-m forest squares into the four categories coniferous, coniferous mixed, broadleaf mixed and broadleaf (BFS GEOSTAT). The classification values were resampled to a resolution of $5 \times 5 \mathrm{~m}$ and averaged per sample area. Dist_f represents the shortest distance from the center of the sample

275 area (i.e. nest locations for territories and center points for control areas) to forest edge, extracted from the swissTLM3D 1.1 C 2014 swisstopo 5704000000 (swisstopo 2014).

\# Table 1 approximately here 
Given the habitat requirements summarized above (Methods/Study species) and the RS variables just introduced, a priori expectations were derived for the probability of wood warbler occurrence and potentially influential habitat variables (Fig. 2, Table 1). Since habitat needs of this species addressed in the past have not distinguished pre-breeding and breeding territory selection, no scale-specific expectations were possible.

\# Fig. 2 approximately here

\section{Data analysis}

To analyze if habitat characteristics of pre-breeding territories $(\mathrm{N}=66)$ and breeding territories $(\mathrm{N}=78)$ differ from what is available in the forested landscape and in the immediate forest vicinity, respectively, pre-breeding territories were compared to their associated pseudoabsences 500-2,000 m away (see above), while breeding territories were compared to their associated field-absences 200-300 m away. Generalized linear mixed-effect models (GLMMs) with logit link and assuming a binomial error distribution were applied with two random effects, namely study area and territory-control pairs nested within study area. For all analyses, the binomial response variable was specified as unoccupied control area (coded as 0) vs. either pre-breeding territory or breeding territory (coded as 1 in either case). All RS variables were standardized $($ mean $=0$, standard deviation $=1)$ prior to analyses.

Model selection and model averaging were based on Akaike Information Criterion (AIC) (Akaike 1974; Everitt 2002), following an approach described by Burnham and Anderson (2002). This multi-model inference approach accounts for model selection uncertainty and leads to more robust inferences compared to inferences based on only one single best model (Burnham and Anderson 2002). For this study, AIC corrected for small 
sample size $(\mathrm{AICc})$ and $\mathrm{AICc}$ differences $(\triangle \mathrm{AICc})$ were calculated for all candidate models (Hurvich and Tsai 1989). Models with $\triangle \mathrm{AICc}$ values $<2$ compared to the best supported one are considered to have similar support, while the others are considered to be less supported by the data (Burnham and Anderson 2002). In addition to $\triangle \mathrm{AICc}$ values, model-averaged estimates, model-averaged standard errors (SE) and 95\% confidence intervals (95\% CI) were calculated for all variables. A 95\% CI excluding 0 indicates that the occurrence of the study species is either positively or negatively related to the respective variable (Mazerolle 2006).

For each thematic group, firstly, a set of candidate models was constructed (withingroup analysis). These sets consisted of models with all variable combinations of the particular group, except that variables correlating more than $|0.5|$ were never included together in the same model, but were instead evaluated in separate (but otherwise identical) models (App. 2). Interactions between the variables were not considered. According to the expectations formulated a priori (Fig. 2), quadratic effects $\left(\mathrm{x} \pm \mathrm{x}^{2}\right)$ were considered for meanVH, meanCH, meanVH>3m, mean $C H>3 m$, maxVH, VH95, pen50_2, meanCC, meanCC_10m, meanCC_15m and meanCC_20m. The null model included the intercept and the two random effects. No more than six RS variables were analyzed jointly in the same model. Including more than six variables could have resulted in overfitting of the models, given the sample sizes available. A variable was considered relevant if 1) it was included in the best supported model or in a model with a $\triangle \mathrm{AICc}$ value $<2$ compared to the best supported one and 2) had a model-averaged estimate across all models per group larger than its model-averaged SE. Secondly, an acrossgroup analysis was performed including only the relevant variables of each thematic group. The candidate model set consisted of models with all combinations of the relevant variables. Again, variables correlating more than $|0.5|$ were never included together in the same model, and six RS variables at most were jointly analyzed in the same model. 
Predictive performance and robustness of the best performing models were evaluated based on area under the receiver operating characteristic curve (AUC) and true skill statistic (TSS). AUC is a threshold-independent measure indicating the model's ability to discriminate presences and absences (Zweig and Campell 1993; Fielding and Bell 1997). Following labels were assigned to AUC values: $0.5=$ no discrimination, $0.7-0.79=$ acceptable, $0.8-0.9=$ excellent, and $>0.9=$ outstanding (Hosmer and Lemeshow 2000). TSS measures overall model performance by correcting the overall accuracy of model predictions by the accuracy expected to occur by chance. TSS is a special case of Cohen's kappa (Cohen 1960), but not dependent on prevalence, which is described by the proportion of observed presences. TSS is defined as sum of sensitivity (proportion of observed presences correctly predicted) and specificity (proportion of observed absences correctly predicted) less one (Allouche et al. 2006). Following labels were assigned to the ranges of Cohen's kappa: $<0.00=$ poor, $0.00-0.20=$ slight, $0.21-0.40=$ fair, $0.41-0.60=$ moderate, $0.61-0.80=$ substantial, $0.81-1.00=$ almost perfect (Landis and Koch 1977). packages AICcmodavg (Mazerolle 2012), lme4 (Bates et al. 2012) and PresenceAbsence (Freeman 2012).

\section{Results}

\section{Pre-breeding territories vs. pseudo-absences}

Within-group analysis - For each thematic group, the best supported models ( $\triangle \mathrm{AICc}<$ 2) always received strong support relative to the null model (App. 4). In the vegetation height group, these models included max $V H$, mean $V H<3 m$, and the quadratic effects of mean $C H$ and $\max V H$. Further, these models included $s d V H$, sdCH>3m, pen50_2, pen5_1, meanCC_10m, 

meanCC_20m. After considering the model-averaged estimates and SE, the following variables were retained for the across-group analyses: the quadratic effects of mean $\mathrm{CH}$, maxVH and pen50_2, and the linear effects of $\operatorname{maxVH}, s d V H, s d C H>3 m$, pen50_2, pen5_1, meanCC_10m, meanCC_20m, slope, r_march and forest_type. Across-group analysis - The best supported models had $\Delta \mathrm{AICc}$ values $>74.7$ to the null model and included $s d V H$, pen50_2, pen5_1, meanCC_10m, meanCC_20m, slope, $r \_$march and dist_f(Table 2). According to the 95\% CI (Table 3), pre-breeding territory occurrence was negatively related to $\operatorname{maxVH}, s d V H$, $s d C H>3 m$ and meanCC_20m, and positively related to pen50_2, meanCC_10m, slope and $r_{-}$march, respectively (Fig. 3). Further, pre-breeding territory occurrence showed a negative quadratic relationship with both meanCH and $\max V H$.

\#Table 2 approximately here\# \#Table 3 approximately here\#

$370 \quad$ \# Fig. 3 approximately here\#

\section{Breeding territories vs. field-absences}

Within-group analysis - For the breeding territories, results of within-group model selection were similar to those of the pre-breeding territories (App. 4). However, the best supported models neither included pen5_1, $r_{-}$march and dist_f nor the quadratic effects of mean $\mathrm{CH}$ and meanCC_20m. However, meanVH and forest_type, and the quadratic effect of VH95 appeared in the best supported models. The following variables were kept for the acrossgroup analyses: meanVH, maxVH, meanVH<3m, sdVH, sdCH>3m, pen50_2, meanCC_10m, meanCC_20m, slope, forest_type and the quadratic effect of $V H 95$. 
model and included meanVH, meanVH<3m, maxVH, sdVH, sdCH>3m, pen50_2, slope, forest_type and the quadratic effect of VH95 (Table 2). Breeding territory occurrence was negatively related to mean $V H, \max V H, s d V H$, $s d C H>3 m$ and meanCC_2Om and positively related to slope, respectively (Table 3, Fig. 4).

\# Fig. 4 approximately here

\section{Model fit}

Discrimination ability of models (best model and models with $\triangle \mathrm{AICc}$ values $<2$ to the best) based on AUC were considered excellent to outstanding with values between 0.84 and 0.93 (App. 5). Model predictive performances based on TSS ranged from moderate to substantial with values between 0.59 and 0.77 .

\section{Discussion}

Territory selection of the wood warbler at two spatial scales was governed by similar factors. Pre-breeding territories were located in areas with intermediate vegetation height, lower vertical diversity, higher penetration rate of the tree layer, larger canopy cover between $10 \mathrm{~m}$ and $20 \mathrm{~m}$ above ground and lower canopy cover above $20 \mathrm{~m}$, increased inclination and higher potential direct solar radiation in March compared to control areas in the wider forested

400 landscape (Table 3). Breeding territories differed from control areas in the immediate forest vicinity by lower vegetation height, lower vertical diversity, lower canopy cover above $20 \mathrm{~m}$ and increased inclination.

Vegetation height (expectation 1) - The results imply that both pre-breeding and breeding territory selection of wood warblers were sensitive to stand height. As expected, 
probability of pre-breeding territory occurrence showed a negative quadratic relationship with mean canopy and maximum vegetation height, indicating an optimum at intermediate heights. In addition, the negative relationship with maximum vegetation height indicates that prebreeding territories were established in areas with smaller trees than available in the wider forested landscape. Likewise, for the breeding territories, the negative relationships with the vegetation height variables suggest that areas were selected that featured smaller trees than what was available in the immediate forest vicinity. Intermediate stand height corresponds to late pole wood (mean diameter at breast height of the hundred thickest trees per hectare $\mathrm{dbh}_{100}$ $=20-30 \mathrm{~cm})$ and young timber $\left(\mathrm{dbh}_{100}=31-40 \mathrm{~cm}\right)($ Cioldi et al. 2010). Stands of these development stages are usually single-layered and characterized by a closed canopy (Korpel 1995; Pontailler et al. 1997; Meyer et al. 2003; Rozenbergar et al. 2007). This allows for an open stem space and inhibits the development of dense regeneration, herbs and shrubs. A relatively open under- and mid-story is conducive to the wood warbler's courtship behavior, which includes song-flights from low branches between tree trunks (Glutz von Blotzheim and Bauer 1991). Moreover, a closed canopy allows for development of a sparse and low-growing ground vegetation cover, a key habitat feature affecting both breeding habitat selection (Pasinelli et al. 2016) and reproductive performance (Grendelmeier et al. 2015) of the wood warbler.

Vertical diversity (expectation 2) - Wood warbler territory occurrence was negatively related to vertical diversity of vegetation and canopy height. Thus, expectation 2 was supported for both scales, suggesting that stands are preferred that are characterized by low tree height diversity of the canopy trees and few gaps. These conclusions are closely connected to the findings from expectation 1 because stands of medium height are characterized by homogeneous stand height (Korpel 1995; Pontailler et al. 1997; Meyer et al. 2003; Rozenbergar et al. 2007). In general, avian diversity in forests is positively related to structural diversity (Scherzinger 1996; Müller 2005; Winter et al. 2005; Mollet et al. 2006; Goetz et al. 
2007; Müller et al. 2009). Thus, while measures aiming at increasing structural diversity within forests appear to promote bird species richness, specialized species such as the wood warbler preferring homogeneously structured forests will not benefit.

Vertical stratification (expectation 3) - Unexpectedly, pre-breeding territory selection was positively related to the penetration rate of the tree layer. This indicates that pre-breeding territories were located in forest stands enabling lidar signals to pass through them more easily than through other forest stands available in the landscape. Penetration rate of the tree layer was not correlated with the lidar-derived canopy cover (App. 2), but negatively related with the field variable number of conifers $\left(\mathrm{r}_{\mathrm{s}}=-0.51, \mathrm{App} .3\right)$ gathered for addressing other questions 440 within the wood warbler project (Pasinelli et al. 2016). This implies that male wood warblers select territories that contain fewer conifers than control areas in the forested landscape. However, the forest type variable (expectation 10) did not receive support. It is likely that the spatial resolution of the data and the classification into four groups representing coniferous to broadleaf forest types was not sufficiently accurate to test for a preference of broadleaf forest

445 stands. Rather, lidar data collection outside the growing season appears to be suited for capturing the proportion of coniferous trees because of their higher amount of canopy reflections compared to deciduous trees.

Canopy cover (expectation 6) - According to this study, canopy cover favoring wood warbler occurrence was high $10 \mathrm{~m}$ above ground (pre-breeding territories) but low $20 \mathrm{~m}$ above 450 ground (pre-breeding and breeding territories). Again, this finding is closely connected with the results concerning vegetation height (expectation 1) and vertical diversity (expectation 2) because pole wood and young timber are characterized by a closed canopy.

Slope (expectation 7) - In line with previous studies, wood warbler occurrence at both the pre-breeding and breeding territory scales was positively related to slope. Several reasons 455 for a preference of slopes by breeding wood warblers have been proposed. First, slope may act as surrogate for some main characteristics of habitat suitability. For example, relatively dense 
middle-aged forest stands along inclined terrain might allow more direct sun radiation to reach the ground, thereby positively affecting ground vegetation cover (i.e., grass tussocks) important for wood warbler nest site choice and nest survival (Grendelmeier et al. 2015; Pasinelli et al. 460 2016), compared to similar forest stands in flat terrain. Second, Mallord et al. (2012) argued that nowadays wood warblers mainly settle in the upland areas of the UK, where grazing has remained the dominant form of land management, maintaining the open woodland structure preferred by wood warblers. Also in Switzerland, wood warbler occurrence has strongly declined in the lowlands (Schmid et al. 1998). However, the argument of grazing is not applicable to Switzerland because wood pasture was already discontinued after the first half of the 19th century due to changes in agricultural practice (Bürgi 1999). Third, when comparing pre-breeding territories to control areas in the wider forested landscape, another explanation for the positive relationship between wood warbler occurrence and slope could be that disturbance due to recreational activity or forest management intensity decreases with increasing

470 inclination. However, recreational activities hardly explain the preference for inclined areas found because all study areas investigated were relatively remote. In addition, distance to trails and paths did not differ between breeding territories and field-absences (Pasinelli et al. 2016). Concerning forest management, inclined areas are often treated less intensively due to increased costs and logistic challenges of timber harvesting. Many study areas are located in

475 areas where the last treatment, a good indicator for forest management intensity, took place 20 to 50 years ago (Duc et al. 2010), and some study areas are situated in forest nature reserves. However, forest management hardly explains the positive relationship between wood warbler occurrence and inclination when comparing breeding territories to what is available in the immediate forest vicinity. A final explanation for the observed relationship with slope might

480 thus be found in the nesting ecology of the wood warbler. Nest entrances are typically oriented horizontally in this species. Nests built at inclined locations, with entrances facing away from the slope, could allow wood warblers to easily escape from nests without getting entangled in 
the vegetation (Piotrowska and Wesolowski 1989). Nest predation accounts for the majority of nest losses in this ground-nesting species (Grendelmeier et al. 2015).

Potential direct solar radiation in March (expectation 8) - Pre-breeding territory selection was positively related to potential direct solar radiation in March. Because solar radiation is highest on south-facing slopes and lowest on north-facing slopes, this finding may explain why wood warbler territories with southern aspect are more common than territories with northern or western aspects (Glutz von Blotzheim and Bauer 1991; Hölzinger 1999;

490 Reinhardt and Bauer 2009). Further, solar radiation might positively influence food availability. Higher food availability on south-facing slopes than on north-facing slopes could attract wood warblers, as Jedrzejewska and Jedrzejewski (1998) and Kühn (2015) reported positive correlations between wood warbler population size and food abundance.

\section{Conclusions}

Many conservation efforts in forests aim at developing open and diversely structured forest stands to promote biodiversity. Structurally rich stands also promote bird species diversity because habitat suitability for many avian forest species is strongly determined by three-dimensional vegetation structure (e.g. Dunlavy 1935; Müller et al. 2009; Zellweger et al.

500 2013). Nevertheless, not all species thrive in structurally rich stands, if these species require specific developmental forest stages. The wood warbler seems to be an example of such a species, because it favors a rather uniform environment. Our study with RS variables corroborates previous field-based studies relating wood warbler habitat to homogeneously structured forests of intermediate age, featuring a closed canopy and low canopy height 505 diversity. Forest management may locally contribute to the deterioration of suitable areas, for example when relatively closed forests are opened up due to harvesting. Likewise, forestry practices that aim either at bringing more light into woodland by selective thinning or that generate forest stands permanently covered with shrubs, bushes and trees of various sizes 
(continuous cover forestry) are not beneficial to the wood warbler. On the other hand, maturing

510 of forest stands also deteriorates habitat quality for this species in the long run. Therefore, forest management at a regional scale should maintain a shifting mosaic of forest patches of different development stages by focusing on sustainable regeneration and a balanced age structure so that suitable stands of even age are always present and new suitable stands are steadily developing. Moreover, areas characterized by abiotic factors identified as relevant for 515 wood warbler occurrence, namely slope and solar radiation, should be identified and managed appropriately. Such areas could represent "safe havens" for this species, given that abiotic factors important for wood warbler occurrence do not change over time, and should thus not be targets of forest management aiming at increasing forest biodiversity, for example by excessive thinning to favor light-demanding species.

That territory selection during both pre-breeding and breeding is governed by similar factors is a novel and important finding for the conservation of this declining passerine. Analyzing habitat needs at two spatial scales allows transferring the inferences of this study to both fine- and broad-scale forest and/or conservation management without struggling with scaling issues. The results suggests that promoting forests consisting of relatively uniform 525 habitat, as outlined above, will serve both to attract prospecting males prior to breeding and to subsequently allow establishment of breeding territories. This simplifies management measures needed to promote suitable habitats for this species as opposed to the situation when different structures affect habitat selection at different spatial scales.

Finally, lidar-derived RS data based on first and last return data acquired during leaf-off 530 conditions appear to be suitable to describe habitat suitability during the breeding season of forest birds, as for example the wood warbler, even at small spatial scales. 


\section{Acknowledgements}

Many thanks to Alexander Grendelmeier and Michael Gerber for collecting data on wood warbler nests and territory locations. We thank Rafael Wüest for his support with the statistical analyses and Peter Rotach for a valuable discussion. We are grateful for helpful comments to previous versions of the manuscript provided by Kurt Bollmann, Jeff HepinstallCymerman and three anonymous reviewers. For financial support, we thank the Swiss National

540 Science Foundation (grant no. 31003A_143879 to G. P. and Raphaël Arlettaz), Hilfsfonds für die Schweizerische Vogelwarte Sempach, PD-Stiftung der Universität Zürich, Styner-Stiftung, Stotzer-Kästli-Stiftung and Lotteriefonds des Kantons Solothurn. 
Table 1 RS variables used in this study, assignment to thematic groups, related expectations (exp.) and support at the pre-breeding territory (PBT) and breeding territory scale (BT). In the expectation column, numbers refer to panels in Fig. 2; after the backslash, the expected relationship is given: quad $=$ negative quadratic relationship $\left(x-x^{2}\right)$, pos $=$ positive linear relationship, neg $=$ negative linear relationship. In the two support columns, the relationships found in the across-group model-selection analysis are indicated for the respective variables (only variables with $95 \% \mathrm{CI}$ excluding zero, Table 3). Highlighted in grey are those relationships matching the a priori expectations in the expectation column.

\begin{tabular}{|c|c|c|c|c|c|c|c|}
\hline Thematic group & Exp. & RS variable & Unit & Definition & Interpretation & Support PBT & Support BT \\
\hline \multirow[t]{3}{*}{ Vegetation height } & $1 /$ quad & meanVH & {$[\mathrm{m}]$} & $\begin{array}{l}\text { mean vegetation } \\
\text { height }\end{array}$ & $\begin{array}{l}\text { MeanVH is an index of vegetation height. A well- } \\
\text { developed overstory leads to a high mean } V H \text {. An } \\
\text { intermediate or low meanVH is expressed by stands with a } \\
\text { well-developed medium layer and scattered or young } \\
\text { stands. }\end{array}$ & & neg \\
\hline & $1 /$ quad & meanCH & {$[\mathrm{m}]$} & $\begin{array}{l}\text { mean canopy } \\
\text { height }\end{array}$ & $\begin{array}{l}\mathrm{MeanCH} \text { is a measure of stand height. MeanCH is low } \\
\text { when either tree height is low or stand structure is scattered } \\
\text { with few large trees present. }\end{array}$ & quad & \\
\hline & $1 /$ quad & meanVH<3m & {$[\mathrm{m}]$} & $\begin{array}{l}\text { mean vegetation } \\
\text { height less than } 3 \\
\mathrm{~m}\end{array}$ & $\begin{array}{l}\text { MeanVH<3m refers to regeneration and underwood. The } \\
\text { variable is around zero if no regeneration and underwood is } \\
\text { present and increasingly above zero, the more young trees }\end{array}$ & & \\
\hline
\end{tabular}




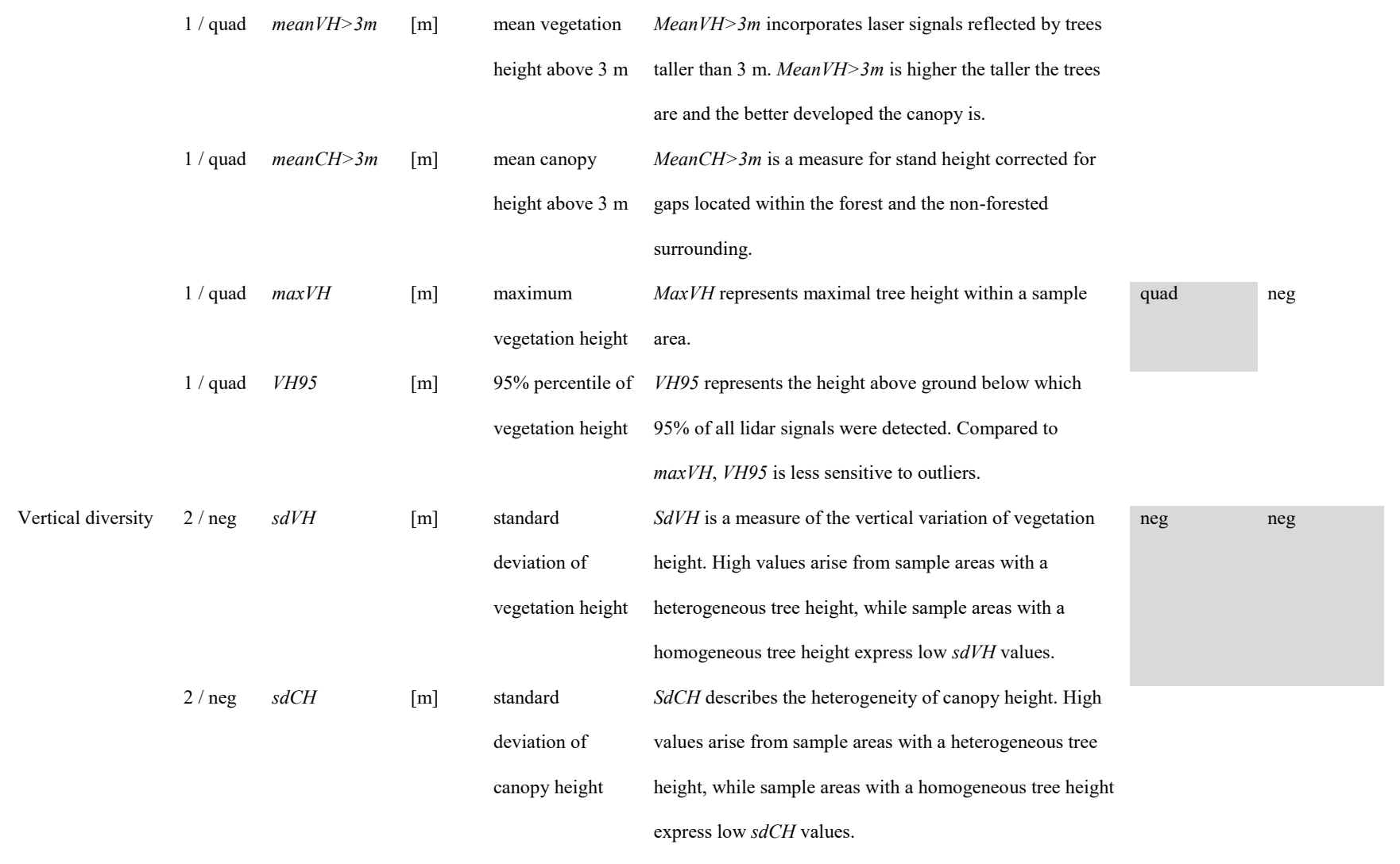


$2 /$ neg $\quad s d C H>3 m \quad[\mathrm{~m}] \quad$ standar

deviation of

canopy height

above $3 \mathrm{~m}$

$3 /$ quad pen50_2

Vertical

stratification

penetration rate

50-2 m above

ground

$\begin{array}{ll}4 / \text { pos pen10_2 } & \text { [\%] } \\ & 10-2 \mathrm{~m} \text { above } \\ & \text { ground }\end{array}$

$5 /$ pos pen5_1

$[\%]$

penetration rate

5-1 m above

ground

Equal to $s d C H, s d C H>3 m$ is a measure of the

heterogeneity of canopy height. In contrast to $\mathrm{sdCH}$,

$s d C H>3 m$ does not consider gaps within the forest or nonforested surroundings.

Pen50_2 describes the penetration rate of the tree layer.

Low values originate from stands with a well-developed

tree layer, while high penetration rates result from scattered

or open stands. For data collected outside the growing

season, pen50_2 expresses lower values for stands with a

high proportion of coniferous trees than for deciduous

stands.

Pen10_2 describes the penetrativeness of the mid-story.

Low penetration rates originate from stands with a well-

developed mid-story, while high penetration rates result

from sparse mid-stories.

Pen5_1 refers to the shrub and regeneration layer. High

pen5_l values result from stands with a sparse shrub and

regeneration layer, while low values originate from stands

with a well-developed shrub and regeneration layer.

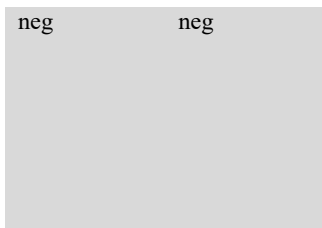

pos 


\begin{tabular}{|c|c|c|c|c|c|c|c|}
\hline \multirow[t]{4}{*}{ Canopy cover } & $6 /$ quad & meanCC & {$[\%]$} & $\begin{array}{l}\text { mean canopy } \\
\text { cover above } 3 \mathrm{~m}\end{array}$ & $\begin{array}{l}\text { MeanCC describes canopy cover of the vegetation equal or } \\
\text { higher than } 3 \mathrm{~m} \text {. High values represent a high canopy } \\
\text { cover, while low values reflect scattered or open stands. }\end{array}$ & & \\
\hline & $6 /$ quad & meanCC_10m & {$[\%]$} & $\begin{array}{l}\text { mean canopy } \\
\text { cover above } 10 \mathrm{~m}\end{array}$ & $\begin{array}{l}\text { High values represent closed stands, while low values } \\
\text { reflect scattered or open stands. }\end{array}$ & pos & \\
\hline & $6 /$ quad & meanCC_15m & {$[\%]$} & $\begin{array}{l}\text { mean canopy } \\
\text { cover above } 15 \mathrm{~m}\end{array}$ & $\begin{array}{l}\text { High values represent closed stands with many trees larger } \\
\text { than } 15 \mathrm{~m} \text {, while low values reflect scattered or open } \\
\text { stands and stands with many tall trees. }\end{array}$ & & \\
\hline & $6 /$ quad & meanCC_20m & {$[\%]$} & $\begin{array}{l}\text { mean canopy } \\
\text { cover above } 20 \mathrm{~m}\end{array}$ & $\begin{array}{l}\text { High values originate from stands with many trees higher } \\
\text { than } 20 \mathrm{~m} \text {, while open or scattered stands and stands with } \\
\text { many trees taller than } 20 \mathrm{~m} \text { express low values. }\end{array}$ & neg & neg \\
\hline \multirow[t]{5}{*}{ Geography } & $7 /$ pos & slope & {$\left[{ }^{\circ}\right]$} & slope & Slope describes mean inclination of the sample area. & pos & pos \\
\hline & $8 /$ pos & $r_{-}$march & {$[10$} & potential direct & $R_{-}$march describes mean potential direct solar radiation in & pos & \\
\hline & & & $\left.\mathrm{MJ} / \mathrm{m}^{2}\right]$ & $\begin{array}{l}\text { solar radiation in } \\
\text { March }\end{array}$ & March of the sample area. & & \\
\hline & $9 /$ pos & forest_type & [index] & forest type & $\begin{array}{l}\text { Forest_type represents mean classification values, reaching } \\
\text { from coniferous (index }=1 \text { ) to broadleaf forest (index }=4 \text { ). }\end{array}$ & & \\
\hline & $10 /$ pos & dist $f$ & {$[\mathrm{~m}]$} & $\begin{array}{l}\text { distance to forest } \\
\text { edge }\end{array}$ & $\begin{array}{l}\text { Dist } f \text { represents the distance of the center of the sample } \\
\text { area to nearest forest edge. }\end{array}$ & & \\
\hline
\end{tabular}


Table 2 Results of model selection for pre-breeding and breeding territories for the acrossgroup analyses. Shown are best-supported models $(\triangle \mathrm{AICc}=0)$ and models with $\Delta$ AICc values $<2$ to the best supported model per spatial scale. The quadratic effect of a variable, composed of a linear and a quadratic component $\left(\mathrm{x} \pm \mathrm{x}^{2}\right)$, is denoted as $(\wedge 2)$. “.." indicates the presence of other models with $\triangle \mathrm{AICc}>2$ to the best model

\begin{tabular}{|c|c|c|c|}
\hline Pre-breeding territory models & $\triangle \mathrm{AICc}$ & Breeding territory models & $\triangle \mathrm{AICc}$ \\
\hline sdVH, pen50_2, meanCC_10m, slope, & & meanVH, sdCH>3m, slope & 0 \\
\hline$r$ _march & 0 & mean $V H>3 m, s d V H, s d C H>3 m$, pen50_2, & \\
\hline pen50_2, meanCC_10m, meanCC_20m, & & slope & 0.56 \\
\hline slope, $r$ march & 0.02 & $\max V H, s d C H>3 m$, pen50_2, slope & 1.10 \\
\hline meanCC_10m, meanCC_20m, slope, & & mean $V H$, mean $V H<3 m$, $s d C H>3 m$, slope & 1.28 \\
\hline$\left.r \_m a r c h, d i s t\right] f$ & 0.73 & meanVH<3m, VH95 (^2), sdCH>3m, slope & 1.54 \\
\hline$s d V H$, pen50_2, meanCC_10m, slope, dist_f & 1.09 & mean $V H<3 m$, maxVH, slope & 1.87 \\
\hline pen5_1, meanCC_10m, meanCC_20m, & & meanVH, sdCH>3m, slope, forest_type & 1.88 \\
\hline slope, $r \_m a r c h$ & 1.84 & $\ldots$ & \\
\hline$\cdots$ & & null model & 60.00 \\
\hline null model & 76.54 & & \\
\hline
\end{tabular}


Table 3 Model-averaged estimates (MAE), standard errors (SE) and 95\% confidence intervals $(95 \% \mathrm{CI})$ of the RS variables included in the across-group analysis. Bold: variables with 95\% CI excluding zero. Variables appearing in the best supported models ( $\triangle$ AICc values $<2)$ are highlighted in grey. The quadratic effect of a variable is denoted as $\left({ }^{\wedge} 2\right)$

\begin{tabular}{|c|c|c|}
\hline RS variable & $\begin{array}{l}\text { Pre-breeding territories } \\
\text { MAE,SE }[95 \% \mathrm{CI}]\end{array}$ & $\begin{array}{l}\text { Breeding territories } \\
\text { MAE, SE }[95 \% \mathrm{CI}]\end{array}$ \\
\hline \multicolumn{3}{|l|}{ Vegetation height } \\
\hline meanVH & & $-1.3 ; 0.3[-1.9 ;-0.8]$ \\
\hline mean $V H<3 m$ & & $-0.3 ; 0.3[-0.9 ; 0.2]$ \\
\hline $\max V H$ & $-1.2 ; 0.3[-1.9 ;-0.5]$ & $-1.4 ; 0.3[-2.0 ;-0.9]$ \\
\hline \multicolumn{3}{|l|}{$\operatorname{meanCH}\left({ }^{\wedge} 2\right)$} \\
\hline linear component & $1.0 ; 0.5[0.0 ; 2.0]$ & \\
\hline quadratic component & $-0.8 ; 0.3[-1.3 ;-0.3]$ & \\
\hline \multicolumn{3}{|l|}{$\max V H\left({ }^{\wedge} 2\right)$} \\
\hline linear component & $-1.3 ; 0.4[-2.0 ;-0.7]$ & \\
\hline quadratic component & $-0.6 ; 0.3[-1.1 ;-0.0]$ & \\
\hline \multicolumn{3}{|l|}{ VH95 (^2) } \\
\hline linear component & & $-1.4 ; 0.3[-2.0 ;-0.8]$ \\
\hline quadratic component & & $-0.3 ; 0.3[-0.8 ; 0.2]$ \\
\hline \multicolumn{3}{|l|}{ Vertical diversity } \\
\hline$s d V H$ & $-1.3 ; 0.5[-2.2 ;-0.4]$ & $-1.3 ; 0.3[-1.9 ;-0.8]$ \\
\hline$s d C H>3 m$ & $-1.4 ; 0.5[-2.3 ;-0.5]$ & $-0.8 ; 0.4[-1.6 ;-0.0]$ \\
\hline \multicolumn{3}{|l|}{ Vertical stratification } \\
\hline pen50_2 & $0.9 ; 0.4[0.1 ; 1.6]$ & $0.4 ; 0.3[-0.1 ; 1.0]$ \\
\hline pen5_1 & $0.4 ; 0.5[-0.5 ; 1.4]$ & \\
\hline \multicolumn{3}{|l|}{ pen50_2(^2) } \\
\hline linear component & $1.0 ; 0.4[0.2 ; 1.8]$ & \\
\hline quadratic component & $-0.1 ; 0.2[-0.5 ; 0.3]$ & \\
\hline \multicolumn{3}{|l|}{ Canopy cover } \\
\hline meanCC_10m & $2.3 ; 0.7[1.0 ; 3.6]$ & $0.4 ; 0.4[-0.3 ; 1.1]$ \\
\hline meanCC_20m & $-1.1 ; 0.4[-1.9 ;-0.4]$ & $-1.0 ; 0.2[-1.5 ;-0.6]$ \\
\hline \multicolumn{3}{|l|}{ Geography } \\
\hline slope & $1.0 ; 0.5[0.0 ; 1.9]$ & $0.6 ; 0.3[0.0 ; 1.2]$ \\
\hline
\end{tabular}


$r$ march

$0.8 ; 0.3[0.2 ; 1.5]$

forest_type

dist $f$
$0.3 ; 0.3[-0.3 ; 0.8]$

$0.6 ; 0.3[-0.1 ; 1.2]$ 
560 Fig. 1 Location of the study areas $(+)$ in northern Switzerland (rectangular insert): 1 Bänkerjoch AG, 2 Belchen SO, 3 Blauen BL, 4 Dittingen BL, 5 Ennenda GL, 6 Erschwil SO, 7 Gündelhart TG, 8 Homberg SO, 9 Hochwald SO, 10 Kleinlützel SO, 11 Langenbruck BL, 12 Lauwil BL, 13 Montsevelier JU, 14 Oltingen BL, 15 Staffelegg SO, 16 Scheltenpass SO 
Fig. 2 Expected relationships a priori derived from the literature between independent 565 variables (x-axis) and the probability of wood warbler occurrence (y-axis). Bold: names of thematic groups and associated expectations (numerals) 
Fig. 3 Wood warbler pre-breeding territory occurrence in relation to the variables of the best supported GLMM $(\bullet=$ territories, $\bigcirc=$ pseudo-absences $)$. Model-averaged estimates of the

570 across-group analysis were used as coefficients. Lines represent the fitted responses for the respective variable (where the other variables were set to their means). Variable description is available in Table $1 . \mathrm{N}_{\text {territories }}=66, \mathrm{~N}_{\text {pseudo-absences }}=66$ 
Fig. 4 Wood warbler breeding territory occurrence in relation to the variables of the best $\operatorname{supported} \operatorname{GLMM}(\bullet=$ territories, $\circ=$ field-absences $)$. Model-averaged estimates of the 575 across-group analysis were used as coefficients. Lines represent the fitted responses for the respective variable (where the other variables were set to their means). Variable description is available in Table $1 . \mathrm{N}_{\text {territories }}=78, \mathrm{~N}_{\text {field-absences }}=78$ 


\section{References}

Akaike H (1974) A new look at the statistical model identification. IEEE T Automat Contr $19: 716-723$

Allouche O, Tsoar A, Kadmon R (2006) Assessing the accuracy of species distribution models: prevalence, kappa and the true skill statistic (TSS). J Appl Ecol 43:1223-1232

Bates D, Maechler M, Bolker B (2012) Linear mixed-effects models using S4 classes (lme4). Package version 0.999999-0. Available from http://cran.rstudio.com/bin/windows/contrib/2.14/

585 (accessed December 2012)

Bellamy PE, Hill RA, Rothery P, Hinsley SA, Fuller RJ, Broughton RK (2009) Willow Warbler Phylloscops trochilus habitat in woods with different structure and management in southern England. Bird Stud 56:338-348

Bellis LM, Pidgeon AM, Radeloff VC, St-Louis V, Navarro JL, Martella MB (2008) Modeling

590 habitat suitability for greater rheas based on satellite image texture. Ecol Appl 18:1956-1966 BirdLife International (2015) European red list of birds. Office for Official Publications of the European Communities, Luxembourg

Bibby CJ (1989) A survey of breeding Wood Warblers Phylloscopus sibilatrix in Britain, 1984-1985. Bird Stud 36:56-72

595 Brambilla M, Falco R, Negri I (2012) A spatially explicit assessment of within-season changes in environmental suitability for farmland birds along an altitudinal gradient. Anim Conserv 15: $638-647$

Brandtbert T, Warner TA, Landenberger RE, McGraw JB (2003) Detection and analysis of individual leaf-off tree crowns in small footprint, high sampling density lidar data from the eastern deciduous forest in North America. Remote Sens Environ 85:290-303 Broughton RK, Hinsley SA, Bellamy PE, Hill RA, Rothery P (2006) Marsh Tit Poecile palustris territories in a British broad-leaved wood. Ibis 148:744-752 
Broughton RK, Ross AH, Freeman SN, Bellamy PE, Hinsley SA (2012) Describing habitat occupation by woodland birds with territory mapping and remotely sensed data: an example

605 using the marsh tit (Poecile palustris). Condor 114:812-822

Bürgi M (1999) A case study of forest change in the Swiss lowlands. Landsc Ecol 14:567-575 Bunnell FL, Huggard DJ (1999) Biodiversity across spatial and temporal scales: problems and opportunities. For Ecol Manage 115: 113-126

Burnham K, Anderson D (2002) Model selection and multimodel inference: a practical

610 information-theoretic approach. 2nd edn. Springer, Berlin Heidelberg New York

Chetkiewicz C-LB, Boyce MS (2009) Use of resource selection functions to identify conservation corridors. J Appl Ecol 46:1036-1047

Cioldi F, Baltensweiler A, Brändli U-B, Duc P, Ginzler C, Herold Bonardi A, Thürig E, Ulmer U (2010) Waldressourcen. In: Brändli U-B (ed) Schweizerisches Landesforstinventar:

615 Ergebnisse der dritten Erhebung 2004-2006. Eidgenössische Forschungsanstalt für Wald, Schnee und Landschaft, WSL, Birmensdorf and Bundesamt für Umwelt, BAFU, Bern Cohen J (1960) A coefficient of agreement for nominal scales. Educ Psychol Meas 20:37-46 Coops NC, Duffe J, Koot C (2010) Assessing the utility of lidar remote sensing technology to identify mule deer winter habitat. Can J Remote Sens 36:81-88

620 Duncan C, Kretz D, Wegmann M, Rabeil T, Pettorelli N (2014) Oil in the Sahara: mapping anthropogenic threats to Saharan biodiversity from space. Philos Trans R Soc B 369:20130191 Dunlavy JC (1935) Studies on the phyto-vertical distribution of birds. Auk 52:425-431 Duc P, Brändli U-B, Bornardi AH, Rösler E, Thürig E, Ulmer U, Frutig F, Rosset C, Kaufmann E (2010) Holzproduktion. In: Brändli U-B (ed) Schweizerisches

625 Landesforstinventar: Ergebnisse der dritten Erhebung 2004-2006. Eidgenössische Forschungsanstalt für Wald, Schnee und Landschaft, WSL, Birmensdorf and Bundesamt für Umwelt, BAFU, Bern 
EIONET (2015) Population status and trends at the EU and Member State levels. Available from http://bd.eionet.europa.eu/article12/summary?period=1\&subject=A314 (accessed

630 November 2015)

Everitt B (2002) The Cambridge dictionary of statistics. 2nd edn. Cambridge University Press, Cambridge

Farrell SL, Collier BA, Skow KL, Long AM, Campomizzi AJ, Morrison ML, Hays KB, Wilkins RN (2013) Using LiDAR-derived vegetation metrics for high-resolution, species

635 distribution models for conservation planning. Ecosphere 4:1-18

Fielding AH, Bell JF (1997) A review of methods for the assessment of prediction errors in conservation presence/absence models. Environ Conserv 24:38-49

Finck P (1990) Seasonal variation of territory size with the little owl (Athene noctua).

Oecologia 83:68-75

640 Freeman E (2012) Presence-Absence Model Evaluation (PresenceAbsence). Package version 1.1.9. Available from http://cran.rstudio.com/bin/windows/contrib/2.14/ (accessed December 2012)

Gerber M (2011) Territory choice of the Wood Warbler Phylloscopus sibilatrix in Switzerland in relation to habitat structure and rodent density. Master thesis, University of Zurich, Zurich 645 Glutz von Blotzheim UN, Bauer KM (1991) Handbuch der Vögel Mitteleuropas. AULAVerlag GmbH, Wiesbaden

Goetz S, Steinberg D, Dubayah R, Blair B (2007) Laser remote sensing of canopy habitat heterogeneity as a predictor of bird species richness in an eastern temperate forest, USA. Remote Sens Environ 108:254-263

650 Goetz SJ, Steinberg D, Betts MG, Holmes RT, Doran PJ, Dubayah R, Hofton M (2010) Lidar remote sensing variables predict breeding habitat of a Neotropical migrant bird. Ecology $91: 1569-1576$ 
Graf RF, Mathys L, Bollmann K (2009) Habitat assessment for forest dwelling species using LiDAR remote sensing: Capercaillie in the Alps. For Ecol Manage 257:160-167

655 Grendelmeier A, Arlettaz R, Gerber M, Pasinelli G (2015) Reproductive performance of a declining forest passerine in relation to environmental and social factors: implications for species conservation. PLoS ONE 10:e0130954

Grubbs FE (1969) Procedures for detecting outlying observations in samples. Technometrics $11: 1-21$

660 Hawbaker TJ, Gobakken T, Lesak A, Trømborg, Contrucci K, Radeloff V (2010) Light detection and ranging-based measures of mixed hardwood forest structure. For Sci 56(3):313326

Hobson KA, Van Wilgenburg SL, Wesolowski T, Maziarz M, Bijlsma RG, Grendelmeier A, Mallord JW (2014) A multi-isotope $\left(\delta^{2} \mathrm{H}, \delta^{13} \mathrm{C}, \delta^{15} \mathrm{~N}\right)$ approach to establishing migratory

665 connectivity in Palearctic-Afrotropical migrants: an example using wood warblers Phylloscopus sibilatrix. Acta Ornithol 49:57-69

Hölzinger J (1999) Die Vögel Baden-Württembergs Singvögel 1. Eugen Ulmer GmbH \& Co, Stuttgart

Hosmer D, Lemeshow S (2000) Applied logistic regression, 2nd edn. John Wiley \& Sons, New 670 York Chichester Weinheim Brisbane Singapore Toronto Hurvich CM, Tsai C-L (1989) Regression and time series model selection in small samples. Biometrika 76(2):297-307

Hutto RL (1985) Habitat selection by nonbreeding, migratory land birds. In Cody ML (ed) Habitat selection in birds, Academic Press, Orlando, pp 455-476

675 Isenburg M (2012) LAStools: award winning software for rapid LIDAR processing. Available from http://www.cs.unc.edu/ isenburg/lastools/ (accessed November 2012) Jedrzejewska B, Jedrzejewski W (1998) Predation in vertebrate communities: the Bialowiezka primeval forest as a case study. Ecol Stud 135:1-450 
Johnson DH (1980) The comparison of usage and availability measurements for evaluating resource preference. Ecology 61:65-71

Jung K, Kaiser S, Böhm S, Nieschulze J, Kalko EKV (2012) Moving in three dimensions: effects of structural complexity on occurrence and activity of insectivorous bats in managed forest stands. J Appl Ecol 49:523-531

Korpel S (1995) Die Urwälder der Westkarpaten. Fischer, Stuttgart Jena New York

685 Landis JR and Koch GG (1977) The measurement of observer agreement for categorical data. Biometrics 33:159-174

Kühn B (2015) The role of caterpillar abundance and phenology for breeding success, territory choice and population size of the declining wood warbler (Phylloscopus sibilatrix). Master thesis, University of Zurich, Zurich

690 Lefsky MA, Cohen WB, Parker GG, Harding DJ (2002) Lidar remote sensing for ecosystem studies. BioSience 52:19-30

Luoto M, Kuusaari M, Toivonen T (2002) Modelling butterfly distribution based on remote sensing data. J Biogeogr 29:1027-1037

Mallord JW, Charman EC, Cristinacce A, Orsman CJ (2012) Habitat associations of Wood

695 Warblers Phylloscopus sibilatrix breeding in Welsh oakwoods. Bird Stud 59:403-415 Mazerolle MJ (2006) Improving data analysis in herpetology: using Akaike's Information Criterion (AIC) to assess the strength of biological hypotheses. Amphibia-Reptilia 27:169-180 Mazerolle MJ (2012) Model selection and multimodel inference based on (Q) AIC (c) (AICcmodavg). Version 1.28 Available from

700 http://cran.rstudio.com/bin/windows/contrib/2.14/ (accessed December 2012) Merrill T, Mattson DJ, Wright RG, Quigley HB (1999) Defining landscapes suitable for restoration of grizzly bears Ursus arctos in Idaho. Biol Conserv 87:231-248 MeteoSchweiz (2014) Normwerte 1981-2010: Niederschlagssumme. Bundesamt für Meteorologie und Klimatologie MeteoSchweiz, Zürich 

Ableitungen für eine naturnahe Buchenwirtschaft. Forstw Cbl 122:47-58

Mollet P, Birrer S, Naef-Daenzer B, Naef-Daenzer L, Spaar R, Zbinden N (2006) Situation der Vogelwelt im Schweizer Wald. Schweizerische Vogelwarte, Sempach Möller AP (1990) Changes in the size of avian breeding territories in relation to the nesting cycle. Anim. Behav. 40:1070-1079

Müller J (2005) Waldstrukturen als Steuergrösse für Artengemeinschaften in kollinen bis submontanen Buchenwäldern. Dissertation, Technische Universität München, München Müller J, Brandl R (2009) Assessing biodiversity by remote sensing in mountainous terrain: the potential of LiDAR to predict forest beetle assemblages. J Appl Ecol 46:897-905

715 Müller J, Moning C, Bässler C, Heurich M, Brandl R (2009) Using airborne laser scanning to model potential abundance and assemblages of forest passerines. Basic Appl Ecol 10:671-681 Müller J, Bae S, Röder J, Chao A, Didham RK (2014) Airborne LiDAR reveals context dependence in the effects of canopy architecture on arthropod diversity. For Ecol Manage 312:129-137

Næsset E (2005) Assessing sensor effects and effects of leaf-off and leaf-on canopy conditions on biophysical stand properties derived from small-footprint airborne laser data. Remote Sens Environ 98:356-370

Nelson R, Keller C, Ratnaswamy M (2005) Locating and estimating the extent of Delmarva fox squirrel habitat using an airborne LiDAR profiler. Remote Sens Environ 96:292-301

725 Ørka HO, Næsset E, Bollandsås OM (2010) Effects of different sensors and leaf-on and leafoff canopy conditions on echo distributions and individual tree properties derived from airborne laser scanning. Remote Sens Environ 114:1445-1461

Palminteri S, Powell GVN, Asner GP, Peres CA (2012) LiDAR measurements of canopy structure predict spatial distribution of a tropical mature forest primate. Remote Sens Environ 127:98-105 
Parent JR and Volin JC (2014) Assessing the potential for leaf-off lidar data to model canopy closure in temperate deciduous forests. ISPRS J Photogramm Remote Sens 95:134-145 Park C (2007) A dictionary of environment and conservation. 1 ed. Oxford University Press, New York

Pasinelli G, Hegelbach J, Reyer H-U (2001) Spacing behavior of the middle spotted woodpecker in central Europe. J Wildl Manage 65:432-441

Pasinelli G, Grendelmeier A, Gerber M, Arlettaz, R (2016) Rodent-avoidance, topography and forest structure shape territory selection of a forest bird. BMC Ecology: in press.

Pavlovic A (2009) Raumnutzung von Waldstrukturen durch Phylloscopus-Arten anhand von Scannerdaten. Diplomarbeit, Fachhochschule Weihenstephan, Freising

Pettorelli N, Kamran S, Turner W (2014) Satellite remote sensing, biodiversity research and conservation of the future. Philos Trans R Soc B 369:20130190

Piotrowska M, Wesolowski T (1989) The breeding ecology and behaviour of the chiffchaff Phylloscopus collybita in primaeval and managed stands of Bialowieza Forest (Poland). Acta Ornithol 25:25-76

Pontailler J-Y, Faille A, Lemée G (1997) Storms drive successional dynamics in natural forests: a case study in Fontainebleau forest (France). For Ecol Manage 98:1-15 Quelle M, Tiedemann G (1972) Strukturanalyse von Waldlaubsängerrevieren im Raum

750 Bielefeld. Abhandlungen aus dem Landesmuseum für Naturkunde zu Münster in Westfalen $34: 95-102$

Reidy JL, Thompson III FR, Amundson C, O’Donnell L (2015) Landscape and local effects on occupancy and densities of an endangered wood-warbler in an urbanizing landscape. Landsc Ecol DOI 10.1007/s10980-015-0250-0

755 Reinhardt A, Bauer H-G (2009) Analyse des starken Bestandesrückgangs beim Waldlaubsänger Phylloscopus sibilatrix im Bodenseegebiet. Vogelwarte 47:23-39 
Rozenbergar D, Mikac S, Anic I, Diaci J (2007) Gap regeneration patterns in relationship to light heterogeneity in two old-growth beech-fir forest reserves in South East Europe. Forestry $80: 431-443$

760 Scherzinger W (1996) Naturschutz im Wald - Qualitätsziele einer dynamischen Waldentwicklung. Ulmer, Stuttgart

Schifferli A, Géroudet P, Winkler R, Jacquat B (1980) Verbreitungsatlas der Brutvögel der Schweiz: kartographische Darstellung des Brutvorkommens aller einheimischen Vogelarten in den Jahren 1972 bis 1976. Schweizerische Vogelwarte, Sempach

765 Schmid H, Luder R, Naef-Daenzer B, Graf R, Zbinden N (1998) Schweizer Brutvogelatlas: Verbreitung der Brutvögel in der Schweiz und im Fürstentum Liechtenstein 1993-1996. Schweizerische Vogelwarte, Sempach

Shaw DC, Freeman EA, Flick C (2002) The vertical occurrence of small birds in an old-growth douglas-fir-western hemlock forest Stand. Northwest Sci 76:322-334

770 Smart LS, Swenson JJ, Christensen NL, Sexton JO (2012) Three-dimensional characterization of pine forest type and red-cockaded woodpecker habitat by small-footprint, discrete-return lidar. For Ecol Manage 281:100-110

Sperduto MB, Congalton RG (1996) Predicting rare orchid (small whorled pogonia) habitat using GIS. PE\&RS 62:1269-1279

775 St.-Louis V, Pidgeon AM, Kuemmerle T, Sonnenschein R, Radeloff VC, Clayton MK, Locke BA, Bash D, Hostert P (2014) Modelling avian biodiversity using raw, unclassified satellite imagery. Philos Trans R Soc B 369:20130197

Swiss Federal Statistical Office (2010) Waldmischungsgrad. Available from http://www.bfs.admin.ch/bfs/portal/de/index/dienstleistungen/geostat/datenbeschreibung/wald mischungsgrad.html (accessed December 2012) 
swisstopo (2012) DOM. Available from http://www.swisstopo.admin.ch/internet/swisstopo/de/home/products/height/dom_dtm-av.html (accessed December 2012)

swisstopo (2013) swissALTI3D. Available from http://www.swisstopo.admin.ch/internet/swisstopo/de/home/products/height/swissALTI3D.htm 1 (accessed April 2013) swisstopo (2014) swiss TLM3D. Available from http://www.swisstopo.admin.ch/internet/swisstopo/de/home/products/landscape/swissTLM3D. html (accessed February 2014)

790 swisstopo (2015) DHM25. Available from http://www.swisstopo.admin.ch/internet/swisstopo/en/home/products/height/dhm25.html (accessed August 2015)

Trainor AM, Walters JR, Morris WF, Sexton J, Moody A (2013) Empirical estimation of dispersal resistance surfaces: a case study with red-cockaded woodpeckers. Landsc Ecol 28:775-767

Vierling KT, Vierling LA, Gould W, Martinuzzi S, Clawges RM (2008) Lidar: shedding new light on habitat characterization and modeling. Front Ecol Environ 6:90-98 Vierling KT, Bässler C, Brandl R, Vierling LA, Weiss I, Müller J (2011) Spinning a laser web: predicting spider distributions using LiDAR. Ecol Appl 21:577-588

800 Vierling LA, Vierling KT, Adam P, Hudak AT (2013) Using satellite and airborne LiDAR to model woodpecker habitat occupancy at the landscape scale. PLoS ONE 8:1-13 Vierling KT, Swift CE, Hudak AT, Vogeler JC, Vierling LA (2014) How much does the time lag between wildlife field-data collection and LiDAR-data acquisition matter for studies of animal distributions? A case study using bird communities. Remote Sens Lett 5:185-193

805 Vogeler JC, Hudak AT, Vierling LA, Vierling KT (2013) Lidar-derived canopy architecture predicts Brown Creeper occupancy of two western coniferous forests. Condor 115:614-622 
Wasser L, Day R, Chasmer L, Taylor A (2013) Influence of vegetation structure on lidarderived canopy height and fractional cover in forested riparian buffers during leaf-off and leafon conditions. PLoS ONE 8:e54776

810 Wesolowski T, Maziarz M (2009) Changes in breeding phenology and performance of Wood Warblers Phylloscopus sibilatrix in a primeval forest: A thirty-year perspective. Acta Ornithol $44: 69-80$

Whittingham MJ, Swetnam RD, Wilson JD, Chamberlan DE, Freckleton RP (2005) Habitat selection by yellowhammers Emberiza citrinella on lowland farmland at two spatial scales:

815 implications for conservation management. J Appl Ecol 42:270-280

Wiktander U, Olsson O, Nilsson SG (2001) Seasonal variation in home-range size, and habitat area requirement of the lesser spotted woodpecker (Dendrocopos minor) in southern Sweden. Biol. Conserv. 100:387-395

Wikar D, Ciach M, Bylicka M, Bylicka M (2008) Changes in habitat use by the common

820 buzzard (Buteo buteo L.) during non-breeding season in relation to winter conditions. Pol J Ecol 56: 119-125

Winter S, Flade M, Schumacher H, Kerstan E, Möller G (2005) The importance of near-natural stand structures for the biocoenosis of lowland beech forests. For Snow and Landsc Res 79:127-144

825 Wood EM, Pidgeon AM, Radeloff VC, Keuler NS (2013) Image texture predicts avian density and species richness. PLoS ONE 8:e63211

Zellweger F, Braunisch V, Baltensweiler A, Bollmann K (2013) Remotely sensed forest structural complexity predicts multi species occurrence at the landscape scale. For Ecol Manage 307:303-312

830 Zimmermann NE, Kienast F (1999) Predictive mapping of alpine grasslands in Switzerland: Species versus community approach. J Veg Sci 10:469-482 
Zweig MH, Campell G (1993) Receiver-operating characteristic (ROC) Plots: A fundamental evaluation tool in clinical medicine. Clin Chem 39:561-577

835 


\section{Appendix 1 Sample sizes per study area}

App. 1 Overview on study areas and sample sizes per study area and spatial scale. The column sample size shows number of pre-breeding territories (and associated control areas; number before comma) and number of breeding territories (and associated control areas; number after comma) per study area. Elevation given as mean elevation above sea level.

\begin{tabular}{|c|c|c|c|c|c|}
\hline $\begin{array}{l}\text { Study area } \\
\text { number }\end{array}$ & Study area & Mean coordinates & Elevation (m) & Size $\left(\mathbf{k m}^{2}\right)$ & Sample size \\
\hline 1 & Bänkerjoch $\mathrm{AG}$ & $645^{\prime} 144$ / 254'539 & 682 & 1.15 & $\overline{1,1}$ \\
\hline 2 & Belchen SO & $627^{\prime} 988$ / $245^{\prime} 763$ & 1,022 & 0.18 & 2,2 \\
\hline 3 & Blauen BL & $605^{\prime} 989$ / 256'391 & 727 & 2.21 & 3,3 \\
\hline 4 & Dittingen BL & $603 ' 249$ / $254^{\prime} 717$ & 620 & 0.67 & 1,1 \\
\hline 5 & Ennenda GL & $725^{\prime} 218$ / $211^{\prime} 059$ & 708 & 0.74 & 2,2 \\
\hline 6 & Erschwil SO & $608^{\prime} 659$ / 247'056 & 712 & 1.28 & 2,2 \\
\hline 7 & Gündelhart TG & $712^{\prime} 618$ / $278^{\prime} 229$ & 543 & 1.33 & 1,1 \\
\hline 8 & Homberg SO & $631^{\prime} 140 / 245^{\prime} 407$ & 861 & 1.19 & 3,5 \\
\hline 9 & Hochwald SO & $616^{\prime} 881$ / $256^{\prime} 293$ & 711 & 1.06 & 3,3 \\
\hline 10 & Kleinlützel SO & $599^{\prime} 946$ / 254'110 & 640 & 0.85 & 8,14 \\
\hline 11 & Langenbruck BL & $626^{\prime} 575 / 245^{\prime} 376$ & 938 & 0.67 & 5,5 \\
\hline 12 & Lauwil BL & $616^{\prime} 981$ / $247^{\prime} 025$ & 990 & 0.52 & 9,11 \\
\hline 13 & Montsevelier JU & $604^{\prime} 131$ / $2466^{\prime} 345$ & 676 & 2.35 & 8,9 \\
\hline 14 & Oltingen BL & $638^{\prime} 000 / 253^{\prime} 403$ & 732 & 0.44 & 1,1 \\
\hline 15 & Staffelegg SO & $647^{\prime} 810 / 253^{\prime} 757$ & 620 & 1.75 & 2,2 \\
\hline 16 & Scheltenpass SO & $613^{\prime} 382$ / 243'854 & 97 & 1.14 & 15,15 \\
\hline
\end{tabular}




\section{Appendix 2 Correlation coefficients of the RS variables}

App. 2 Spearman's rank correlation coefficients $\left(\mathrm{r}_{\mathrm{s}}\right)$ of the RS variables. Above the diagonal: breeding territories and field-absences $(\mathrm{N}=156)$,

\begin{tabular}{|c|c|c|c|c|c|c|c|c|c|c|c|c|c|c|c|c|c|c|c|c|c|}
\hline & $\overrightarrow{5}$ & 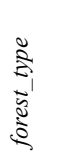 & $\begin{array}{l}0 \\
\vdots \\
\vdots \\
\vdots \\
\vdots \\
\vdots\end{array}$ & $\frac{\check{\Xi}}{s}$ & 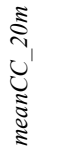 & 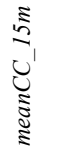 & 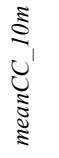 & $\begin{array}{l}U \\
\Xi \\
\Xi \\
\Xi\end{array}$ & $\begin{array}{l}-1 \\
\approx \\
\Xi\end{array}$ & $\begin{array}{l}N_{1} \\
\Xi^{\prime} \\
\vdots \\
\vdots\end{array}$ & $\begin{array}{l}N_{1} \\
\tilde{n}^{\prime} \\
\vdots \\
\vdots \\
\vdots\end{array}$ & 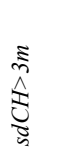 & 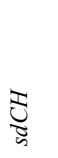 & 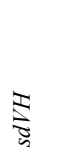 & $\stackrel{2}{\Xi}$ & 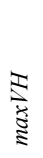 & 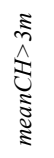 & $\begin{array}{l}\underset{N}{\Xi} \\
\stackrel{\Xi}{\Xi} \\
\stackrel{\Xi}{\Xi}\end{array}$ & 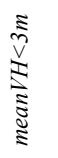 & 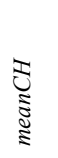 & $\begin{array}{l}\nwarrow \\
\Xi \\
\cong\end{array}$ \\
\hline meanVH & 0.2 & -0.1 & -0.2 & -0.3 & 0.7 & 0.7 & 0.5 & 0.3 & 0.1 & 0.2 & -0.5 & 0.0 & -0.0 & 0.6 & 0.8 & 0.7 & 0.8 & 0.8 & -0.0 & 0.8 & - \\
\hline meanCH & 0.2 & 0.1 & -0.2 & -0.2 & 0.9 & 0.9 & 0.6 & 0.2 & 0.3 & 0.5 & -0.1 & -0.0 & 0.0 & 0.9 & 0.9 & 0.8 & 1.0 & 1.0 & -0.2 & - & 0.8 \\
\hline mean $V H<3 m$ & -0.1 & -0.3 & -0.0 & 0.2 & -0.1 & -0.3 & -0.3 & -0.1 & -0.7 & -0.5 & -0.3 & 0.5 & 0.2 & -0.2 & -0.1 & 0.1 & -0.2 & -0.2 & - & -0.3 & -0.2 \\
\hline mean $V H>3 m$ & 0.2 & 0.1 & -0.3 & -0.2 & 0.9 & 0.8 & 0.4 & 0.0 & 0.4 & 0.6 & 0.1 & -0.0 & 0.2 & 0.9 & 0.9 & 0.9 & 1.0 & - & -0.3 & 0.8 & 0.7 \\
\hline mean $\mathrm{CH}>3 \mathrm{~m}$ & 0.2 & 0.1 & -0.3 & -0.3 & 0.9 & 0.8 & 0.4 & 0.1 & 0.3 & 0.6 & 0.0 & 0.0 & 0.2 & 0.9 & 1.0 & 0.9 & - & 1.0 & -0.3 & 0.9 & 0.7 \\
\hline $\max V H$ & 0.1 & -0.0 & -0.3 & -0.2 & 0.8 & 0.5 & 0.1 & -0.1 & 0.0 & 0.3 & -0.0 & 0.4 & 0.4 & 0.8 & 0.9 & - & 0.6 & 0.6 & 0.0 & 0.4 & 0.4 \\
\hline VH95 & 0.1 & 0.0 & -0.3 & -0.2 & 0.9 & 0.7 & 0.3 & -0.0 & 0.2 & 0.4 & -0.0 & 0.2 & 0.3 & 0.9 & - & 0.9 & 0.8 & 0.8 & -0.1 & 0.6 & 0.6 \\
\hline$s d V H$ & 0.1 & 0.2 & -0.2 & -0.2 & 0.9 & 0.6 & 0.2 & -0.1 & 0.3 & 0.6 & 0.3 & 0.1 & 0.3 & - & 0.9 & 0.8 & 0.9 & 0.9 & -0.2 & 0.7 & 0.5 \\
\hline$s d C H$ & -0.1 & -0.2 & -0.2 & -0.0 & 0.1 & -0.3 & -0.7 & -0.8 & -0.3 & -0.1 & 0.2 & 0.8 & - & 0.6 & 0.6 & 0.7 & 0.3 & 0.4 & 0.1 & -0.1 & -0.0 \\
\hline$s d C H>3 m$ & -0.1 & -0.2 & -0.2 & 0.0 & 0.0 & -0.4 & -0.6 & -0.5 & -0.5 & -0.4 & -0.0 & - & 0.8 & 0.3 & 0.6 & 0.7 & 0.1 & 0.1 & 0.4 & -0.2 & -0.1 \\
\hline pen50_2 & -0.1 & 0.4 & 0.2 & 0.2 & 0.0 & -0.0 & -0.2 & -0.4 & 0.4 & 0.6 & - & 0.2 & 0.4 & 0.3 & 0.1 & 0.1 & 0.1 & 0.1 & -0.1 & 0.2 & -0.6 \\
\hline pen10_2 & 0.1 & 0.4 & 0.1 & 0.0 & 0.5 & 0.6 & 0.4 & 0.0 & 0.8 & - & 0.5 & -0.4 & -0.1 & 0.5 & 0.2 & 0.1 & 0.6 & 0.6 & -0.6 & 0.5 & 0.2 \\
\hline
\end{tabular}




\begin{tabular}{|c|c|c|c|c|c|c|c|c|c|c|c|c|c|c|c|c|c|c|c|c|c|}
\hline pen5_1 & 0.2 & 0.3 & 0.0 & -0.1 & 0.3 & 0.5 & 0.5 & 0.2 & - & 0.9 & 0.3 & -0.5 & -0.2 & 0.3 & 0.1 & -0.1 & 0.4 & 0.4 & -0.8 & 0.4 & 0.1 \\
\hline meanCC & 0.1 & 0.2 & 0.2 & -0.1 & 0.2 & 0.5 & 0.8 & - & 0.2 & 0.1 & -0.5 & -0.6 & -0.8 & -0.2 & -0.3 & -0.4 & -0.0 & -0.1 & -0.1 & 0.4 & 0.3 \\
\hline meanCC_10m & 0.2 & 0.3 & 0.1 & -0.1 & 0.5 & 0.8 & - & 0.9 & 0.5 & 0.4 & -0.4 & -0.7 & -0.8 & 0.0 & -0.1 & -0.3 & 0.3 & 0.3 & -0.4 & 0.6 & 0.5 \\
\hline meanCC_15m & 0.2 & 0.3 & -0.0 & -0.1 & 0.8 & - & 0.8 & 0.6 & 0.5 & 0.6 & -0.2 & -0.5 & -0.4 & 0.4 & 0.3 & 0.0 & 0.6 & 0.6 & -0.4 & 0.8 & 0.6 \\
\hline meanCC_20m & 0.1 & 0.2 & -0.1 & -0.1 & - & 0.7 & 0.4 & 0.1 & 0.3 & 0.5 & -0.0 & 0.0 & 0.2 & 0.9 & 0.8 & -0.6 & 0.9 & 0.9 & -0.2 & 0.9 & 0.7 \\
\hline slope & -0.2 & 0.3 & 0.5 & - & -0.2 & -0.0 & 0.1 & 0.2 & -0.2 & -0.1 & -0.0 & -0.1 & -0.3 & -0.3 & -0.3 & -0.1 & -0.3 & -0.3 & 0.4 & -0.1 & -0.2 \\
\hline$r_{-}$march & -0.1 & 0.6 & - & 0.4 & -0.2 & 0.2 & 0.3 & 0.4 & 0.1 & 0.1 & 0.0 & -0.4 & -0.5 & -0.4 & -0.5 & -0.6 & -0.3 & -0.3 & 0.0 & -0.1 & -0.2 \\
\hline forest_type & 0.0 & - & 0.6 & 0.3 & 0.0 & 0.3 & 0.4 & 0.4 & 0.2 & 0.2 & 0.1 & -0.4 & -0.5 & -0.1 & -0.3 & -0.4 & -0.1 & -0.1 & -0.1 & 0.1 & -0.1 \\
\hline
\end{tabular}




\section{Appendix 3 Correlation coefficients RS variables and field variables}

App. 3 Spearman's rank correlation coefficients $\left(\mathrm{r}_{\mathrm{s}}\right)$ between RS and field variables (Pasinelli et al. 2016) for breeding territories and fieldabsences $(\mathrm{N}=116)$ : Correlations $\geq|0.50|$ are printed in bold

\begin{tabular}{|c|c|c|c|c|c|c|c|c|c|c|c|c|c|c|c|}
\hline & 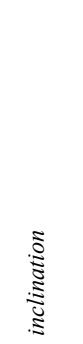 & 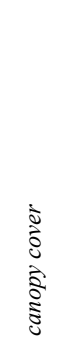 & $\begin{array}{l}\bar{\Xi} \\
\overline{8} \\
\bar{\Xi} \\
\bar{\Xi} \\
\bar{\Xi} \\
\stackrel{0}{0}\end{array}$ & 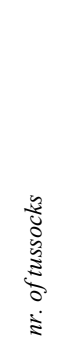 & 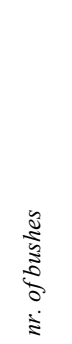 & $\begin{array}{l}\Xi \\
\Xi \\
\vdots \\
\Xi\end{array}$ & 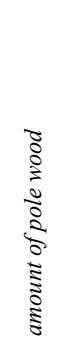 & 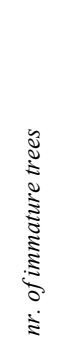 & 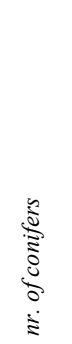 & 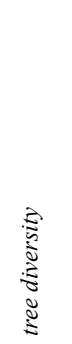 & 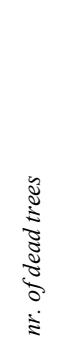 & 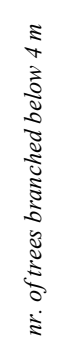 & 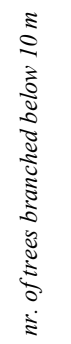 & 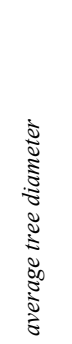 & 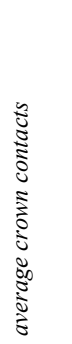 \\
\hline$\overline{\text { meanVH }}$ & -0.34 & 0.08 & -0.16 & -0.40 & 0.03 & -0.36 & -0.36 & -0.35 & 0.14 & -0.06 & -0.15 & -0.45 & -0.44 & 0.53 & 0.06 \\
\hline meanCH & -0.26 & 0.14 & -0.25 & -0.47 & -0.03 & -0.45 & -0.51 & -0.32 & -0.16 & -0.27 & -0.22 & -0.54 & -0.52 & 0.58 & 0.14 \\
\hline meanVH $<3 m$ & 0.08 & 0.08 & -0.13 & -0.11 & 0.08 & 0.04 & 0.14 & -0.03 & 0.16 & 0.11 & -0.01 & 0.11 & 0.06 & -0.09 & 0.12 \\
\hline mean $V H>3 m$ & -0.27 & 0.10 & -0.22 & -0.44 & 0.00 & -0.49 & -0.55 & -0.33 & -0.20 & -0.32 & -0.25 & -0.57 & -0.56 & 0.58 & 0.12 \\
\hline mean $C H>3 m$ & -0.29 & 0.11 & -0.24 & -0.47 & -0.01 & -0.48 & -0.54 & -0.36 & -0.16 & -0.31 & -0.25 & -0.56 & -0.55 & 0.59 & 0.11 \\
\hline $\max V H$ & -0.30 & 0.09 & -0.29 & -0.55 & 0.06 & -0.51 & -0.49 & -0.49 & -0.08 & -0.26 & -0.33 & -0.53 & -0.56 & 0.56 & 0.13 \\
\hline VH95 & -0.28 & 0.11 & -0.27 & -0.52 & 0.04 & -0.47 & -0.50 & -0.42 & -0.09 & -0.25 & -0.29 & -0.52 & -0.54 & 0.61 & 0.15 \\
\hline$s d V H$ & -0.21 & 0.08 & -0.25 & -0.45 & 0.05 & -0.45 & -0.53 & -0.31 & -0.26 & -0.33 & -0.28 & -0.49 & -0.48 & 0.55 & 0.11 \\
\hline$s d C H$ & -0.07 & -0.12 & -0.02 & -0.15 & 0.28 & -0.22 & -0.10 & -0.36 & 0.08 & -0.03 & -0.26 & -0.06 & -0.17 & 0.10 & -0.04 \\
\hline
\end{tabular}




\begin{tabular}{|c|c|c|c|c|c|c|c|c|c|c|c|c|c|c|c|}
\hline$s d C H>3 m$ & 0.01 & -0.07 & -0.11 & -0.23 & 0.30 & -0.19 & -0.01 & -0.37 & 0.12 & 0.08 & -0.27 & -0.01 & -0.12 & 0.05 & 0.08 \\
\hline pen50_2 & 0.19 & 0.00 & -0.08 & 0.03 & -0.03 & -0.04 & -0.13 & 0.13 & -0.51 & -0.30 & -0.04 & -0.00 & 0.02 & -0.07 & 0.06 \\
\hline pen10_2 & 0.04 & 0.19 & -0.16 & -0.14 & -0.17 & -0.23 & -0.41 & 0.05 & -0.48 & -0.40 & -0.11 & -0.34 & -0.27 & 0.26 & 0.17 \\
\hline pen5_1 & -0.00 & 0.07 & -0.01 & 0.04 & -0.17 & -0.16 & -0.34 & 0.08 & -0.27 & -0.22 & -0.09 & -0.26 & -0.19 & 0.26 & 0.07 \\
\hline meanCC & -0.07 & 0.19 & -0.11 & -0.10 & -0.18 & 0.06 & -0.00 & 0.13 & 0.01 & -0.02 & 0.11 & -0.08 & 0.01 & 0.08 & 0.09 \\
\hline meanCC_ $10 m$ & -0.09 & 0.23 & -0.19 & -0.17 & -0.29 & -0.09 & -0.20 & 0.08 & -0.17 & -0.17 & 0.08 & -0.27 & -0.15 & 0.25 & 0.15 \\
\hline meanCC_ $15 \mathrm{~m}$ & -0.13 & 0.24 & -0.29 & -0.35 & -0.25 & -0.30 & -0.43 & -0.09 & -0.27 & -0.28 & -0.04 & -0.46 & -0.37 & 0.47 & 0.21 \\
\hline meanCC_20m & -0.22 & 0.18 & -0.29 & -0.50 & -0.09 & -0.43 & -0.53 & -0.30 & -0.19 & -0.29 & -0.22 & -0.54 & -0.52 & 0.58 & 0.20 \\
\hline slope & 0.81 & 0.09 & -0.14 & 0.17 & -0.28 & 0.13 & 0.10 & 0.23 & -0.30 & 0.07 & 0.09 & 0.16 & 0.21 & -0.17 & 0.27 \\
\hline$r_{-}$march & 0.41 & 0.17 & -0.11 & 0.16 & -0.28 & 0.19 & 0.10 & 0.30 & -0.31 & 0.00 & 0.03 & 0.17 & 0.24 & -0.12 & 0.27 \\
\hline forest_type & 0.20 & 0.12 & -0.10 & -0.05 & -0.22 & -0.02 & -0.01 & 0.12 & -0.49 & -0.22 & -0.10 & 0.01 & 0.03 & -0.12 & 0.13 \\
\hline dist_f & -0.02 & -0.07 & 0.02 & -0.02 & -0.00 & -0.09 & -0.10 & -0.05 & -0.13 & -0.14 & 0.02 & -0.12 & -0.14 & 0.12 & -0.07 \\
\hline
\end{tabular}




\section{Appendix 4 Results of within-group model selection}

App. 4 Results of within-group model selection for pre-breeding and breeding territories.

Shown are best-supported models $(\triangle \mathrm{AICc}=0)$ and models with $\Delta \mathrm{AICc}$ values $<2$ to the best supported model per spatial scale. The quadratic effect of a variable, composed of a linear and a quadratic component $\left(x \pm x^{2}\right)$, is denoted as $\left({ }^{\wedge} 2\right)$

\begin{tabular}{|c|c|c|c|}
\hline Pre-breeding territory models & $\Delta \mathrm{AICc}$ & Breeding territory models & $\Delta \mathrm{AICc}$ \\
\hline \multicolumn{4}{|l|}{ Vegetation height } \\
\hline meanCH $\left({ }^{\wedge} 2\right), \max V H$ & 0 & meanVH, maxVH & 0 \\
\hline meanCH $\left({ }^{\wedge} 2\right), \max V H\left({ }^{\wedge} 2\right)$ & 0.25 & mean $V H<3 m$, VH95 $(\wedge 2)$ & 0.22 \\
\hline mean $C H\left({ }^{\wedge} 2\right)$, mean $V H<3 m$, max $V H$ & 1.45 & $\max V H$ & 0.44 \\
\hline \multirow{2}{*}{$\begin{array}{l}\text { mean } C H(\wedge 2), \text { mean } V H<3 m, \max V H(\wedge 2) \\
\ldots\end{array}$} & 1.66 & mean $V H<3 m, \max V H(\wedge 2)$ & 1.41 \\
\hline & & $\max V H(\wedge 2)$ & 1.82 \\
\hline \multirow[t]{2}{*}{ null model } & 42.91 & $\cdots$ & \\
\hline & & null model & 51.14 \\
\hline \multicolumn{4}{|l|}{ Vertical diversity } \\
\hline$s d V H, s d C H>3 m$ & 0 & $s d V H, s d C H>3 m$ & 0 \\
\hline$s d C H>3 m$ & 0.88 & $\cdots$ & \\
\hline$\cdots$ & & null model & 43.40 \\
\hline null model & 37.02 & & \\
\hline \multicolumn{4}{|l|}{ Vertical stratification } \\
\hline pen50_2,pen5_1 & 0 & pen50_2 & 0 \\
\hline pen50_2 $\left({ }^{\wedge} 2\right)$, pen $5 \_1$ & 0.87 & null model & 1.20 \\
\hline pen5_1 & 1.36 & pen50_2(^2) & 1.78 \\
\hline \multicolumn{4}{|l|}{$\ldots$} \\
\hline null model & 11.34 & & \\
\hline \multicolumn{4}{|l|}{ Canopy cover } \\
\hline meanCC_10m, meanCC_20m & 0 & meanCC_10m, meanCC_20m & 0 \\
\hline meanCC_10m, meanCC_20m $\left({ }^{\wedge} 2\right)$ & 1.58 & $\ldots$ & \\
\hline .. & & null model & 32.15 \\
\hline null model & 58.80 & & \\
\hline \multicolumn{4}{|l|}{ Geography } \\
\hline \multirow{2}{*}{$\begin{array}{l}\text { slope, } r \text { _march, dist_f } \\
\ldots\end{array}$} & 0 & slope,forest_type & 0 \\
\hline & & slope & 0.22 \\
\hline \multirow[t]{2}{*}{ null model } & 45.87 & $\ldots$ & \\
\hline & & null model & 14.67 \\
\hline
\end{tabular}




\section{Appendix 5 Accuracy measures}

App. 5 Model performance: area under the receiver operating characteristic curve (AUC) $( \pm \mathrm{SD})$, true skill statistic (TSS) $( \pm \mathrm{SD})$. All numbers are shown in $\%$. The quadratic effect of a variable is denoted as $(\wedge 2)$. Shown are best supported models ( $\triangle \mathrm{AICc}$ values $<2$ )

\begin{tabular}{lll}
\hline Models & AUC & TSS \\
\hline Pre-breeding territories & & \\
sdVH, pen50_2, meanCC_10m, slope, r_march & $91.9 \pm 2.5$ & $75.8 \pm 5.6$ \\
pen50_2, meanCC_10m, meanCC_20m, slope, r_march & $92.2 \pm 2.5$ & $75.8 \pm 5.7$ \\
meanCC_10m, meanCC_20m, slope, r_march, dist_f & $93.2 \pm 2.2$ & $75.8 \pm 5.6$ \\
sdVH, pen50_2, meanCC_10m, slope, dist_f & $91.6 \pm 2.5$ & $71.2 \pm 6.1$ \\
pen5_1, meanCC_10m, meanCC_20m, slope, $r \_m a r c h$ & $92.2 \pm 2.4$ & $77.3 \pm 5.5$ \\
Breeding territories & & \\
meanVH, sdCH>3m, slope & $85.4 \pm 3.0$ & $62.8 \pm 6.2$ \\
meanVH $>3 m$, sdVH, sdCH>3m, pen50_2, slope & $85.5 \pm 3.1$ & $61.5 \pm 6.3$ \\
maxVH, sdCH>3m, pen50_2, slope & $84.7 \pm 3.1$ & $60.3 \pm 6.2$ \\
meanVH, meanVH<3m, sdCH>3m, slope & $86.1 \pm 3.0$ & $66.7 \pm 5.9$ \\
meanVH<3m, VH95 (^2), sdCH>3m, slope & $84.8 \pm 3.1$ & $59.0 \pm 6.4$ \\
meanVH<3m, maxVH, slope & $83.9 \pm 3.2$ & $59.0 \pm 6.4$ \\
meanVH, sdCH>3m, slope, forest_type & $86.0 \pm 2.9$ & $65.4 \pm 6.0$ \\
\hline
\end{tabular}



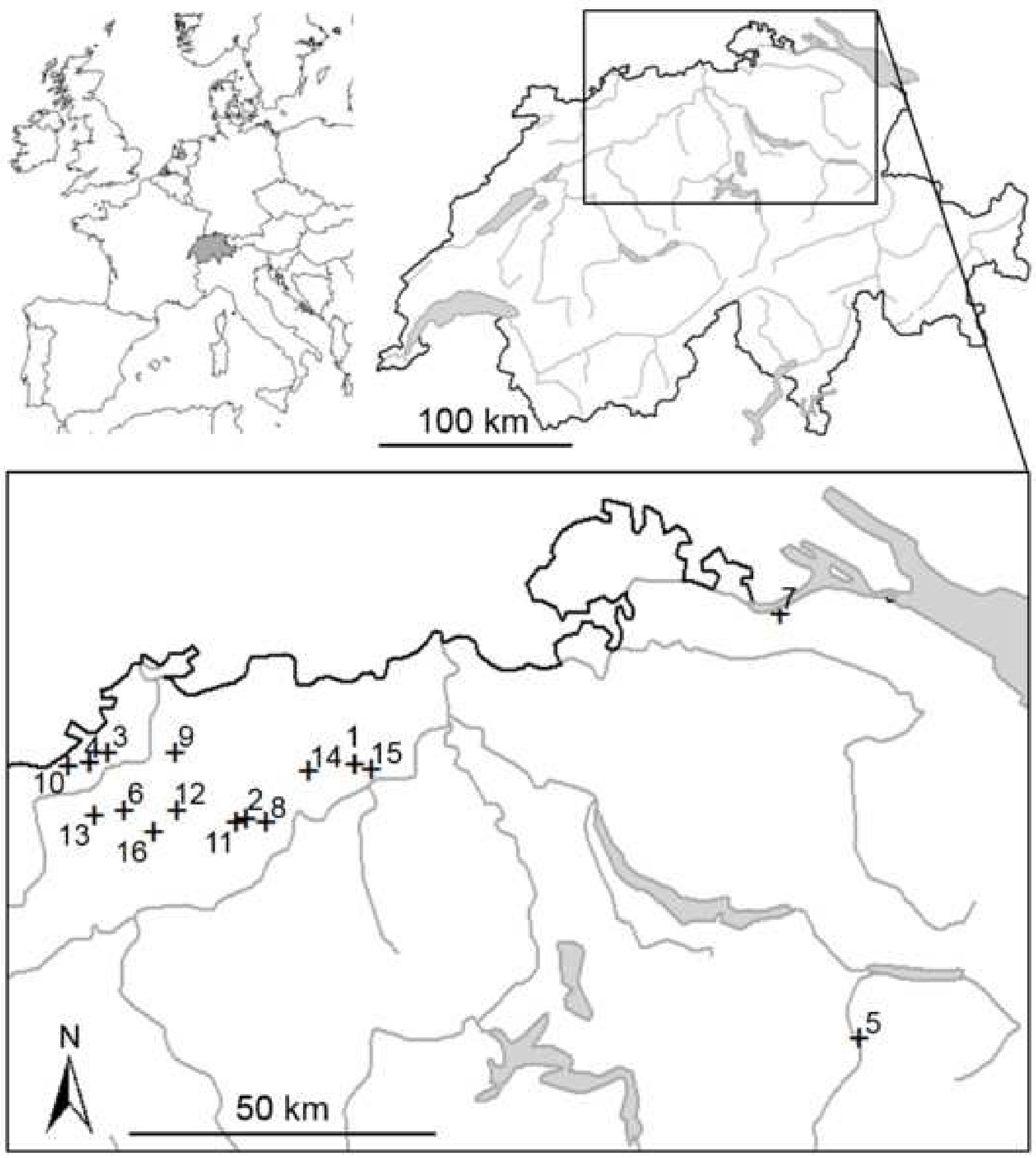


\section{Vegetation height Vertical diversity Vertical stratification (3-5)}

1

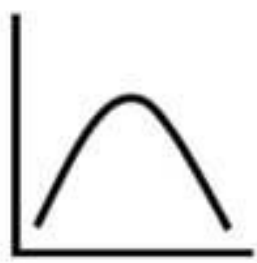

vegetation height

\section{Canopy cover}

6

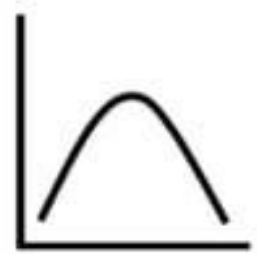

canopy cover
2

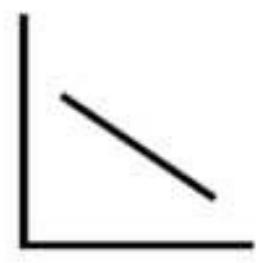

standard deviation of vegetation and canopy height

\section{Geography (7-10)}

7

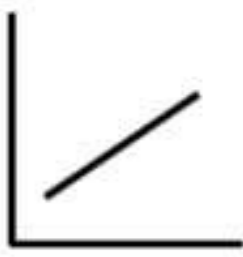

slope
3

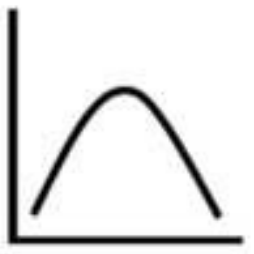

penetration rate of the tree layer

penetration rate of the mid-story layer

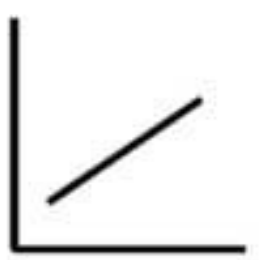

penetration rate of the shrub and regeneration layer

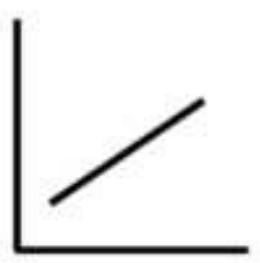

\section{0}

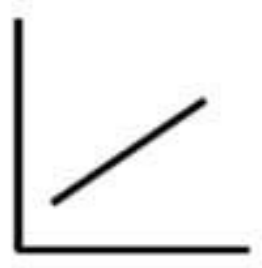

proportion of broadleaf trees

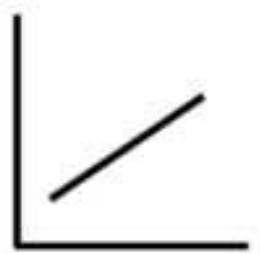

distance to forest edge 

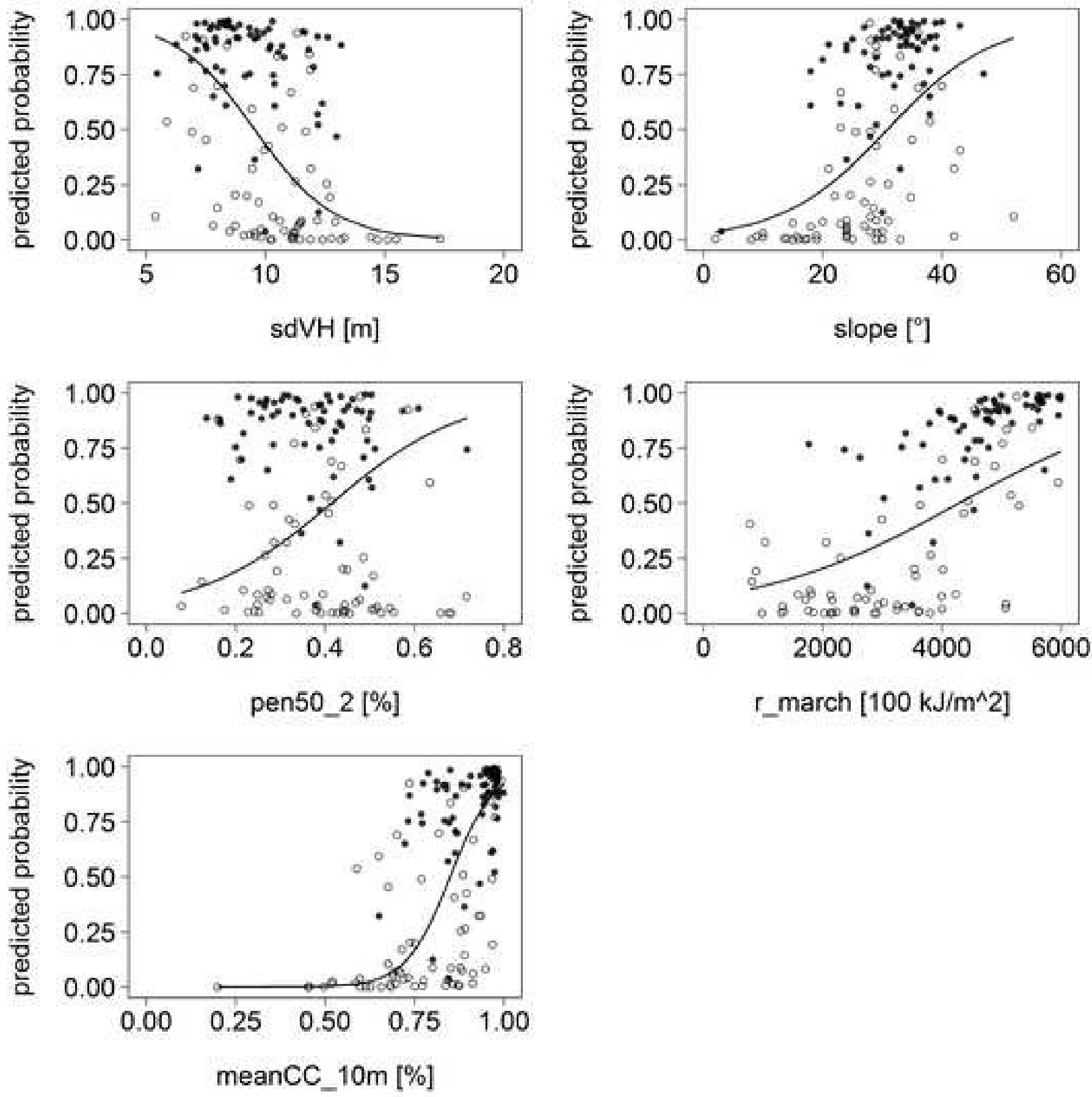

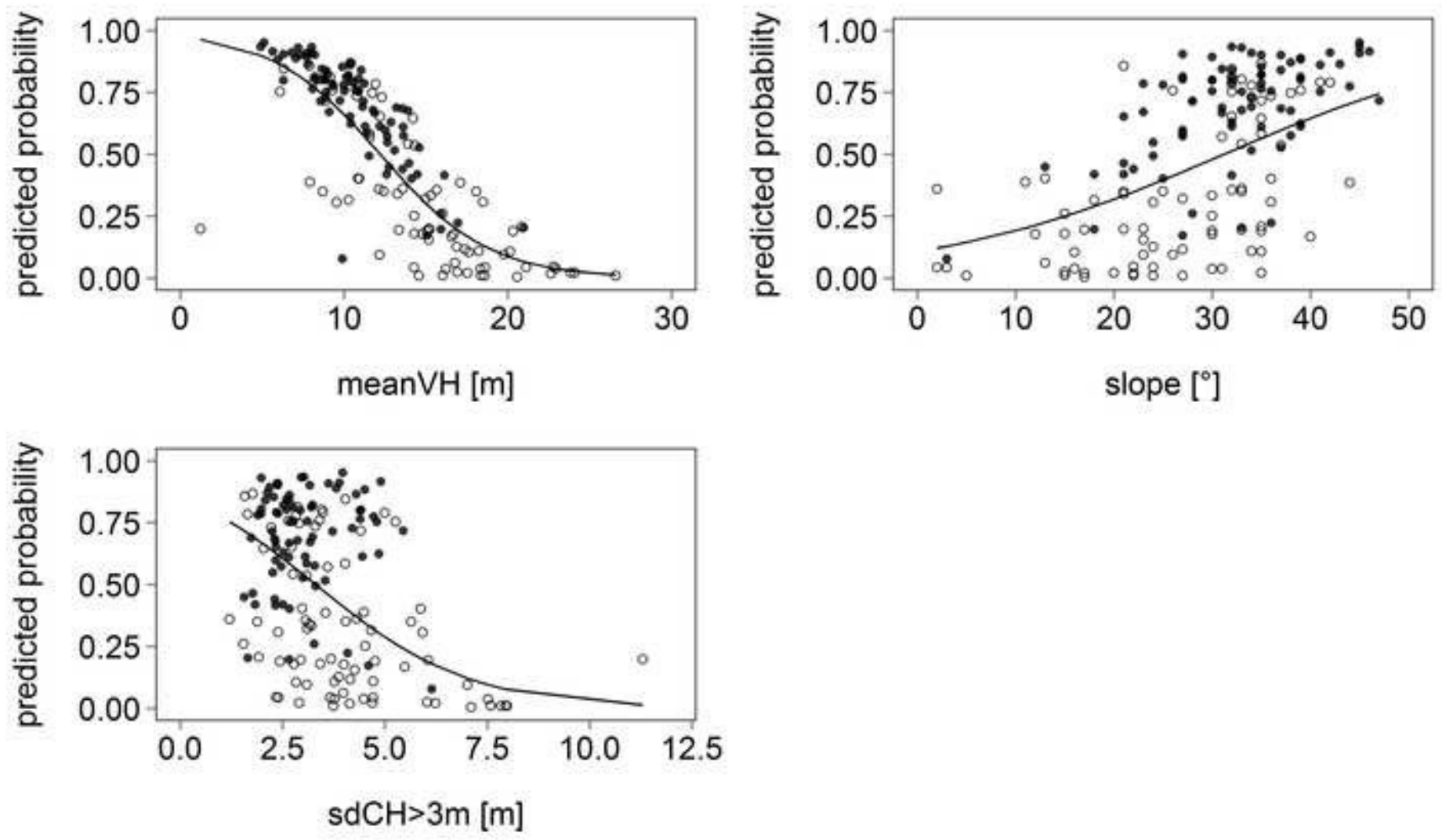